\title{
Flora e estrutura do componente arbóreo da floresta do Parque Ecológico Quedas do Rio Bonito, Lavras, MG, e correlações entre a distribuição das espécies e variáveis ambientais ${ }^{1}$
}

\author{
Paulo Eduardo Dalanesi ${ }^{2,4}$, Ary Teixeira de Oliveira-Filho ${ }^{3}$ e Marco Aurélio Leite Fontes ${ }^{3}$
}

Recebido em 13/08/2003. Aceito em 31/03/2004

\begin{abstract}
RESUMO - (Flora e estrutura do componente arbóreo da floresta do Parque Ecológico Quedas do Rio Bonito, Lavras, MG, e correlações entre a distribuição das espécies e variáveis ambientais). Os objetivos deste trabalho foram (a) descrever a composição florística e a estrutura da comunidade arbórea da floresta do Parque Ecológico Quedas do Rio Bonito, Lavras, MG (21²0’S, 4458’WGW, 1.000-1.300m de altitude); e (b) avaliar as correlações entre a distribuição das espécies e variáveis ambientais em três trechos da floresta. Foram registradas a espécie, a circunferência a altura do peito (CAP) e a altura total de indivíduos com CAP $\geq 15,7 \mathrm{~cm}$ amostrados em 80 parcelas de 10×30m distribuídas em três transecções distanciadas em 480m. Variáveis ambientais foram obtidas por parcela a partir de análises químicas e texturais de amostras do solo superficial $(0-20 \mathrm{~cm}$ de profundidade) e de um levantamento topográfico das transecções. O levantamento florístico conduzido fora e dentro das parcelas registrou 384 espécies pertencentes a 182 gêneros e 68 famílias botânicas. O perfil florístico foi característico das florestas de altitude da Região Sudeste do Brasil. As 4.137 árvores e 213 espécies inventariadas nas parcelas apresentaram alto índice de diversidade de Shannon $\left(H^{\prime}=4,56\right.$ nats.ind. $\left.{ }^{-1}\right)$ provavelmente relacionado com a forte heterogeneidade ambiental e a baixa dominância ecológica. Uma análise de correspondência canônica identificou o fator borda e a classe de drenagem como as variáveis ambientais mais fortemente correlacionadas com a distribuição das abundâncias das espécies.
\end{abstract}

Palavras-chave: candeal, diversidade, comunidade arbórea, floresta de altitude, solos, topografia

\begin{abstract}
Flora and structure of the arboreal component of the forest of the Parque Ecológico Quedas do Rio Bonito, Lavras, Minas Gerais State, and correlations between species distribution and environmental variables). The objectives of the present contribution were (a) to describe the floristic composition and structure of the tree community of the forests of the Parque Ecológico Quedas do Rio

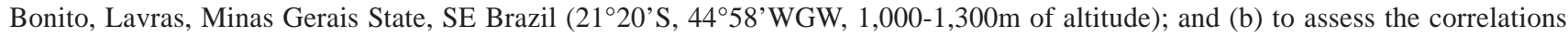
between species distribution and environmental variables in three forest sections. Individual trees with the circumference at breast height (cbh), the total height and species name were registered for individuals with cbh $\geq 15.7 \mathrm{~cm}$ surveyed in 80 plots of $10 \times 30 \mathrm{~m}$ of dimensions distributed into three transects spaced at $480 \mathrm{~m}$ intervals. Environmental variables were obtained for each plot from textural and chemical analyses of soil samples $(0-20 \mathrm{~cm}$ of depth), and a topographic survey of the sample transects. The floristic survey carried out both inside and outside plots registered 384 species belonging to 182 genera and 68 families. The floristic features were characteristic of the montane forests of southeastern Brazil. The 4,137 trees and 213 species surveyed in the plots yielded a high Shannon diversity index $\left(H^{\prime}=4.56\right.$ nats.ind. $\left.{ }^{-1}\right)$ which was probably related to a high environmental heterogeneity and low ecological dominance. A canonical correspondence analysis (CCA) identified the edge factor and drainage class as the variables most strongly correlated with the species' abundance distribution.
\end{abstract}

Key words: diversity, elfin forest, tropical montane forest, soils, topography, tree community

\section{Introdução}

A vegetação primitiva da região do Alto Rio Grande, ao sul de Minas Gerais (entre $21^{\circ} 00^{\prime}-22^{\circ} 20^{\prime} \mathrm{S}$ e $43^{\circ} 50^{\prime}-45^{\circ} 00^{\prime} \mathrm{W}$ ), compreendia um complexo mosaico composto de manchas de floresta, cerrado, campo de altitude e campo rupestre (Eiten 1982). Esta notável variação fisionômica da vegetação deve-se a dois motivos principais. Em primeiro lugar, a região abriga uma das áreas de transição entre os domínios do cerrado e da floresta Atlântica sensu lato. Em segundo lugar, esta transição verifica-se em pleno domínio da serra da Mantiqueira, cujo relevo acidentado promove grande variação ambiental e

\footnotetext{
1 Trabalho integrante do Subprojeto Estratégias para conservação e manejo da biodiversidade em fragmentos de florestas semidecíduas, executado pela EMBRAPA Recursos Genéticos, a Universidade Federal de Lavras (UFLA) e Universidade de Brasília (UnB) e integrante do Projeto de Conservação e Utilização Sustentável da Diversidade Biológica Brasileira (PROBIO), supervisionado pelo Ministério do Meio Ambiente (MMA), gerido pelo Conselho Nacional de Desenvolvimento Científico e Tecnológico (CNPq) e apresentado pelo governo brasileiro ao GEF/BIRD.

2 Faculdade de Engenharia Florestal, Fundação Integrada Municipal de Ensino Superior, CEP 75830-000, Mineiros, GO, Brasil

3 Departamento de Ciências Florestais, Universidade Federal de Lavras, CEP 37200-000, Lavras, MG, Brasil

4 Autor para correspondência: dalanesi@hotmail.com
} 
vegetacional, com fisionomias peculiares nas maiores altitudes. De maneira geral, as fisionomias de campo rupestre e campo de altitude estão associadas aos solos mais rasos, enquanto, nos mais profundos ocorrem cerrados ou florestas, discriminados pela fertilidade e regime de água dos solos e pela freqüência de incêndios (Oliveira-Filho et al. 1994b).

O Parque Ecológico Quedas do Rio Bonito (PEQRB), localizado ao sul do município de Lavras, constitui uma valiosa amostra da vegetação primitiva da região do Alto Rio Grande, pois seus quatro tipos fisionômicos principais - floresta, cerrado, campo rupestre e campo de altitude - encontram-se bem representados e razoavelmente preservados. De acordo com Oliveira-Filho \& Fluminhan-Filho (2000), os campos de altitude e campos rupestres ocorrem principalmente nas áreas mais elevadas e com solos mais rasos; o cerrado, nas áreas mais baixas e com solos mais profundos; e as florestas concentram-se no fundo dos vales. Na transição para os campos, a fisionomia das florestas diferencia-se em uma faixa ecotonal denominada candeal, devido à predominância da candeia (Eremanthus erythropappus (DC.) MacLeish).

O Parque abriga notável diversidade de espécies de plantas em uma área relativamente pequena, o que atraiu a atenção de pesquisadores da Universidade Federal de Lavras e de outras instituições, que vêm realizando ali vários levantamentos florísticos (OliveiraFilho \& Fluminhan-Filho 2000). A floresta do PEQRB distribui-se nas encostas adjacentes ao córrego dos Vilas Boas e possui área total de 74,4ha, o que a caracteriza como o maior fragmento florestal contínuo do município de Lavras (L.T. Oliveira, dados não publicados). Sua vegetação pode ser classificada como floresta estacional semidecidual montana, de acordo com o sistema do IBGE (Veloso et al. 1991), ou como floresta semidecídua alto-montana do domínio da Floresta Atlântica, de acordo com Oliveira-Filho \& Fontes (2000). Estudos quantitativos e ecológicos da vegetação desta floresta iniciaram-se com OliveiraFilho et al. (1994a), em um segmento contínuo, e Rondon-Neto et al. (2000), em uma área em regeneração.

O presente trabalho teve como objetivo básico expandir os estudos quantitativos e ecológicos da comunidade arbórea da floresta do Parque Ecológico Quedas do Rio Bonito. Ao trecho amostrado por Oliveira-Filho et al. (1994a) foram acrescentados mais dois, aumentando a área amostrada de 0,48ha para 2,40ha. As coletas de material botânico dentro e fora da área amostral também incrementaram substan- cialmente o levantamento florístico da área. Os objetivos específicos do trabalho foram (a) descrever a composição da flora arbórea da floresta do Parque Ecológico Quedas do Rio Bonito; (b) descrever a estrutura comunitária e estrutura fisionômica da floresta em diferentes hábitats de solo identificados em três trechos da floresta; e (c) avaliar as correlações entre a distribuição das abundâncias das espécies e variáveis ambientais.

\section{Material e métodos}

Área de estudo - O Parque Ecológico Quedas do Rio Bonito (PEQRB) está localizado no extremo sul do município de Lavras, Minas Gerais, junto à divisa com o município de Ingaí e entre as coordenadas geográficas

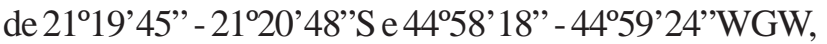
com altitudes variando de 1.000 a $1.300 \mathrm{~m}$ (Fig. 1). O Parque conta com uma área de 209,7ha e é de propriedade da Fundação Abraham Kasinski (FAK), à qual foi doado pela municipalidade em 22/julho/1994. O PEQRB está localizado a aproximadamente $13 \mathrm{~km}$ do centro de Lavras pela estrada Lavras-Luminárias, que o delimita ao sul. Sua área compreende a microbacia do córrego dos Vilas Boas, à montante da antiga barragem de captação de água, apoiando-se em um dos contrafortes da serra do Carrapato, que, juntamente com as vizinhas serras da Bocaina, do Faria, do Campestre, da Estância e do Pombeiro, constituem, ao mesmo tempo, uma disjunção da serra do Espinhaço e sua ligação com o complexo da Mantiqueira. As principais rochas no PEQRB são os quartzitos e micaxistos, nas áreas mais altas (superfície de erosão Gondwana), e os gnaisses graníticos leucocráticos e quartzitos, nas áreas mais baixas (superfície de erosão pós-Gondwana), e os solos predominantes são Neossolos Litólicos e Cambissolos Háplicos (Curi et al. 1990).

De acordo com a classificação de Köppen, o padrão climático da região do $\mathrm{PEQRB}$ enquadra-se no tipo Cwb, ou seja, temperado mesotérmico com verões brandos e suaves e estiagens de inverno. A temperatura média anual situa-se em torno de $19,3^{\circ} \mathrm{C}$, a do mês mais frio (junho) oscila entre 13 e $16^{\circ} \mathrm{C}$ e a do mês mais quente (janeiro), entre 21 e $23^{\circ} \mathrm{C}$. A precipitação média anual é de 1.493mm, com chuvas mal distribuídas durante o ano e concentradas no verão, $67 \%$ do total precipitando entre novembro e fevereiro. O inverno tem cerca de quatro meses, com pequeno déficit hídrico, entre 10 e $30 \mathrm{~mm}$, de acordo com o balanço hídrico de Thorntwaite e Mather (Golfari 1975). 


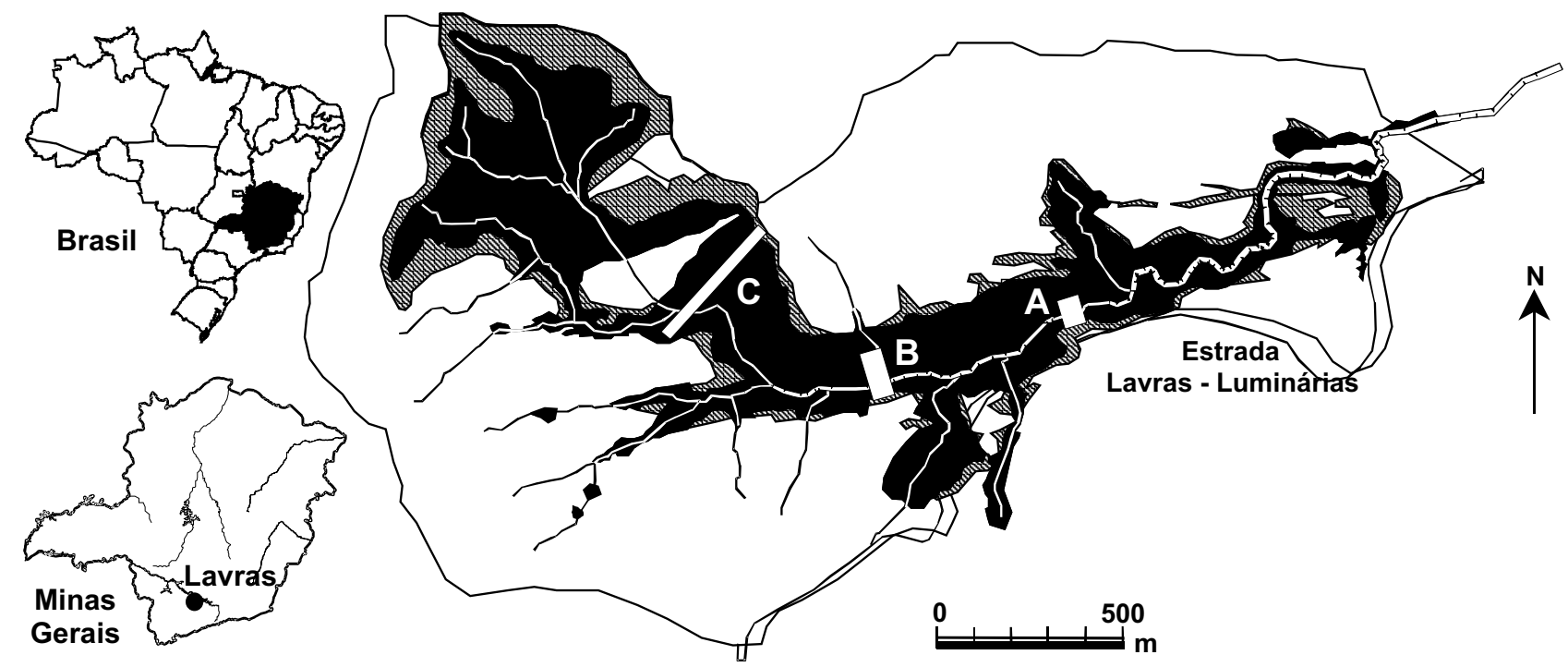

Figura 1. Mapa do Parque Ecológico Quedas do Rio Bonito (PEQRB), município de Lavras, MG, mostrando sua situação geográfica, a distribuição da floresta semidecídua, candeal e formações abertas (campo de altitude, campo rupestre e cerrado) no interior do Parque e a localização das três transecções amostrais (A, B e C). $\mathbf{\square}$ = Floresta semidecídua; $\mathbb{Z}$ = Candeal; $\square$ = Formações abertas.

Inventário da comunidade arbórea - A amostragem foi realizada em três transecções demarcadas no interior da floresta do PEQRB, com áreas de 0,48, 0,78 e 1,14ha e separadas por uma distância de $480 \mathrm{~m}$, totalizando área amostral de 2,40ha (Fig. 1). As transecções, denominadas A, B e C, foram compostas por, respectivamente, 16, 26 e 38 parcelas contíguas de $10 \times 30 \mathrm{~m}$, totalizando 80 parcelas (Fig. 2). As transecções foram dispostas de maneira a cortar a calha do córrego dos Vilas Boas e estender-se nas duas encostas adjacentes, resultando em um alinhamento perpendicular ao sentido predominante do curso d'água. A forma e disposição das parcelas foram escolhidas de forma a obedecer ao princípio expresso por Causton (1988), segundo o qual formas retangulares, dispostas de maneira que o maior comprimento seja perpendicular à direção do gradiente principal presumido, são mais adequadas para estimar os parâmetros da vegetação. Desta forma, o lado menor das parcelas retangulares foi disposto paralelamente ao alinhamento da transecção com o objetivo de investigar a influência do gradiente topográfico na vegetação e nas características dos solos. As transecções A e B, que são mais curtas, empregaram dois alinhamentos contíguos de parcelas e a transecção C, mais longa, apenas um alinhamento.

A transecção A corresponde ao primeiro inventário realizado na floresta do PEQRB, em 1989, cujos resultados foram publicados por Oliveira-Filho et al. (1994a). Os inventários das transecções B e C foram realizados em 2000 e 2001, respectivamente. Nos inventários de A e B foram feitas medições de circunferência a altura do peito (CAP) e do solo (CAS) em cada árvore com CAS $\geq 15,7 \mathrm{~cm}$. No inventário de $\mathrm{C}$, foram medidas somente as CAPs de árvores com $\mathrm{CAP} \geq 15,7 \mathrm{~cm}$ (equivalente a um diâmetro de 5,0cm). O presente trabalho reúne as informações dos três inventários e as padroniza pelos critérios da transecção C. Indivíduos com caules múltiplos foram incluídos quando a raiz quadrada da soma dos quadrados das CAPs era superior ao limite estabelecido. Foram registrados, para cada indivíduo, o nome da espécie, o valor da CAP (medida com fita métrica) e a altura (estimada com o auxílio de varas graduadas). Cada árvore recebeu uma plaqueta de alumínio numerada, identificando a parcela e o indivíduo. Alguns indivíduos de espécies abundantes e bem conhecidas foram identificados no campo, enquanto os demais tiveram material botânico coletado para posterior identificação. Foram realizadas também coletas adicionais em caminhadas de varredura por todo o fragmento florestal, com o propósito de complementar o levantamento florístico. A herborização do material botânico foi feita no Herbário do Departamento de Biologia da Universidade Federal de Lavras (Herbário ESAL) e a coleção de referência foi incorporada ao seu acervo. A identificação do material botânico foi realizada com a utilização de coleções botânicas já existentes no 


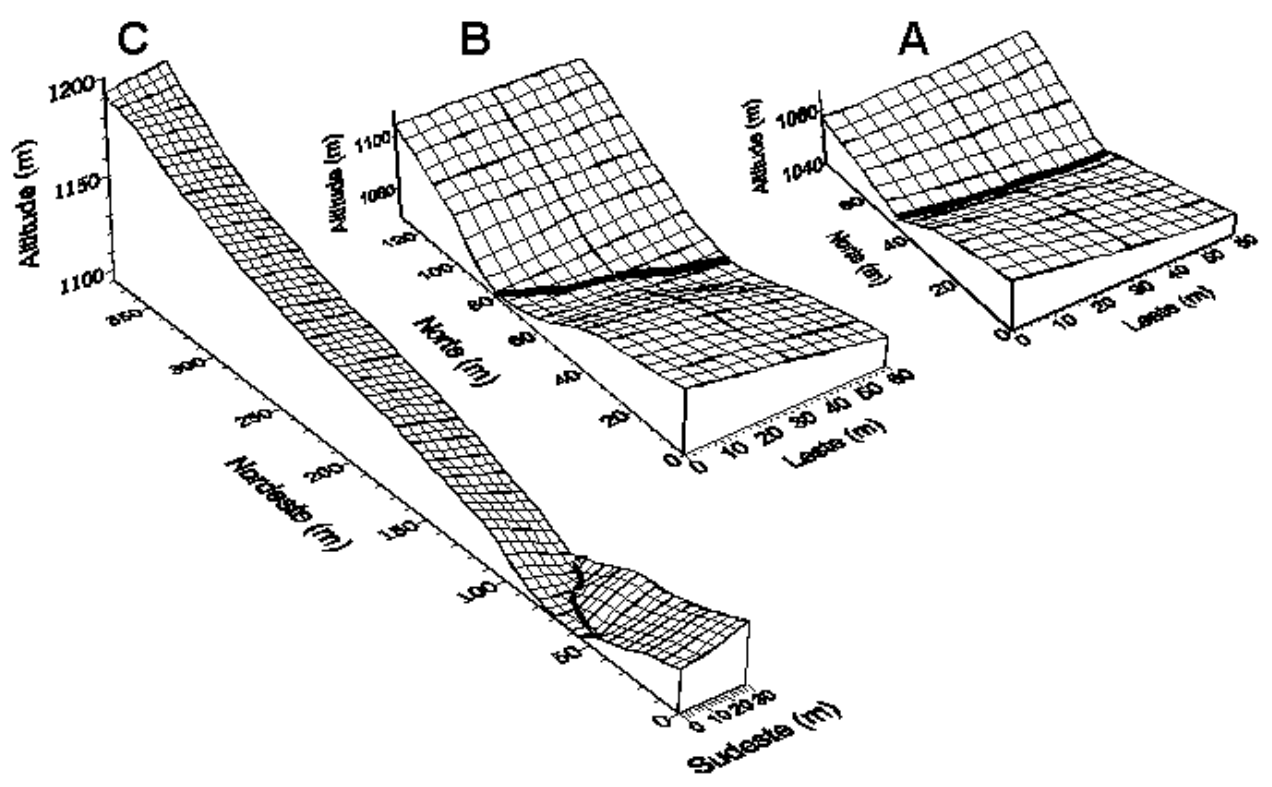

Classes de solo:

田 Neossolos Litólicos

$\square$ Neossolos Regolíticos

曰 Cambissolos Lépticos

$\square$ Cambissolos Típicos

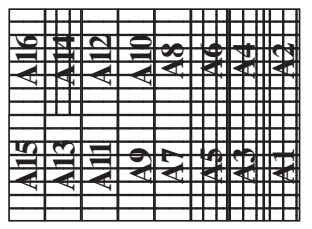

rio

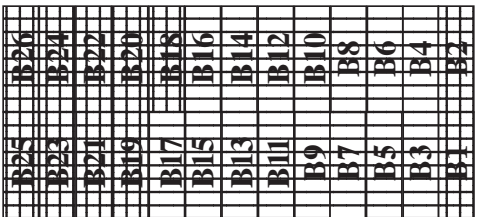

rio

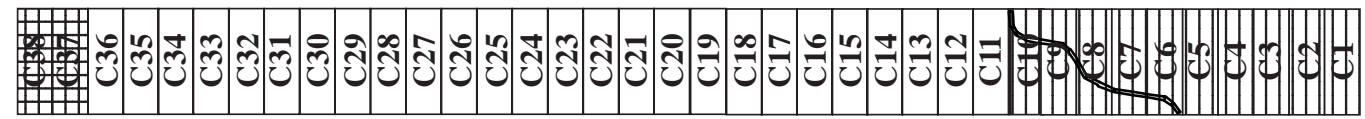

Figura 2. Grades de superfície das três transecções amostrais (A, B e C) utilizadas para amostrar a floresta do PEQRB, Lavras, MG, mostrando a topografia e a distribuição das 80 parcelas de $30 \times 10 \mathrm{~m}$. O espaçamento entre linhas de grade é de $5 \mathrm{~m}$. Note-se que a escala da transecção C é menor que a das outras duas. O esquema abaixo mostra a identificação e classificação dos solos das 80 parcelas. A identidade da parcela é feita pela transecção (A, B e C) mais um número de ordem.

Herbário ESAL e também por meio de consultas à literatura, a especialistas e a coleções dos Herbários do Jardim Botânico do Rio de Janeiro (RB), Instituto de Botânica de São Paulo (SP) e Universidade Estadual de Campinas (UEC). As espécies de angiospermas (todas exceto Cyatheaceae, Podocarpaceae e Araucariaceae) foram classificadas nas famílias reconhecidas pelo Angiosperm Phylogeny Group II (APG II 2003).

Levantamento das variáveis ambientais - Foi realizado levantamento topográfico das três transecções amostrais. A inclinação do terreno foi medida com o auxílio de hipsômetro de Suunto, sendo anotados os desníveis entre os vértices das parcelas e calculadas as distâncias verticais. Com essas medidas, foram traçadas curvas de nível em intervalos de $5 \mathrm{~m}$ a partir da margem do córrego, onde a cota era conhecida.
Por meio das cotas foi confeccionada uma grade de superfície, formando uma representação tridimensional das três transecções (Fig. 2), com o auxílio do programa SURFER versão 5.0, da Golden Software. A cota dos quatro vértices de cada parcela permitiu a obtenção das variáveis topográficas cota média, desnível (diferença entre as cotas máxima e mínima) e distância vertical (diferença entre cota média e cota do córrego) (Botrel et al. 2002).

Os solos de cada parcela foram classificados de acordo com o novo Sistema Brasileiro de Classificação de Solos (EMBRAPA 1999) chegando até ao nível de subgrupo, ou $4^{\circ}$ nível categórico. As classes de solo foram utilizadas em análises comparativas da comunidade arbórea, em subamostras consideradas como ‘hábitats de solo’. A variável ordinal drenagem foi obtida para cada parcela por meio da atribuição de 
números de ordem (ranking) às classes de drenagem definidas pela EMBRAPA (1999) em cada classe de solo amostrada. Para obter as variáveis químicas e texturais do solo, coletaram-se amostras simples de cerca de $1 \mathrm{~L}$ de solo superficial $(0-20 \mathrm{~cm}$ de profundidade) no centro de cada parcela. As amostras foram enviadas para o Laboratório de Análise de Solos do Departamento de Ciência do Solo da Universidade Federal de Lavras para análises químicas e texturais, de acordo com os métodos descritos pela EMBRAPA (1997). As variáveis do solo obtidas foram: $\mathrm{pH}$; teores de P, K, Ca, Mg e Al; saturação por bases (V); matéria orgânica e teores de areia, silte e argila.

Para avaliar o efeito borda na distribuição das espécies foi produzido um 'fator borda' para cada parcela, de acordo com o método concebido por Oliveira-Filho et al. (1997). O fator borda consiste do comprimento linear do contorno da borda medido entre dois (ou mais) pontos de intercepto com um círculo cujo raio tem origem no centro da parcela. O comprimento deste raio representaria o raio de ação máxima do efeito borda sobre a comunidade arbórea, tendo sido utilizado o mesmo valor de $100 \mathrm{~m}$ adotado por Espírito-Santo et al. (2002) e Souza et al. (2003) em fragmentos florestais da mesma região. No presente caso, a borda da floresta foi definida no limite entre o candeal e o campo. Ainda que possa ser visto como ecótono entre floresta e campo, o candeal apresenta, na área de estudos, uma fisionomia claramente florestal e apresenta limites abruptos com o campo e transições mais graduais e imprecisas com o interior da floresta.

Descrição da estrutura da comunidade e estrutura fisionômica - Para cada espécie amostrada nas parcelas foram calculados os seguintes parâmetros fitossociológicos: densidade absoluta, densidade relativa, freqüência absoluta, freqüência relativa, dominância absoluta, dominância relativa e o valor de importância(VI), obtido por meio da soma dos três parâmetros relativos citados (Mueller-Dombois \& Ellenberg 1974). Estes parâmetros foram calculados tanto para a amostra total como para subamostras definidas por hábitats de solo.

Para expressar a diversidade de espécies arbóreas na amostra total e nas subamostras definidas pelos hábitats de solo, foram calculados o índice de diversidade de Shannon $\left(H^{\prime}\right)$, o índice de eqüabilidade de Pielou ( $\left.J^{\prime}\right)$ (Krebs 1989), a densidade média de espécies por parcelas e os estimadores 'jackknife' de primeira e segunda ordem para o número total de espécies (Heltsche \& Forrester 1983; Palmer 1991). Os valores de $H^{\prime}$ obtidos para as subamostras de cada hábitat de solo foram comparados aos pares pelo teste de $t$ de Hutcheson (Zar 1996). A densidade de espécie por parcela foi comparada entre os hábitats de solo com análise de variância seguida de um teste de TukeyKramer.

A densidade e a área basal por hectare, bem como a altura e o diâmetro médios, foram comparados entre os hábitats de solo com análises de variância seguidas de testes de Tukey-Kramer. Foram preparadas distribuições de densidade de árvores por classes de diâmetro e altura para os hábitats de solo. No caso dos diâmetros, foram empregados intervalos de classe com amplitudes crescentes para compensar o forte decréscimo da densidade nas classes de tamanho maiores, típico da distribuição em J-invertido. Estes intervalos permitem uma melhor representação das classes diamétricas maiores e de baixa densidade, o que é desejável em comparações gráficas (OliveiraFilho et al. 2001; Botrel et al. 2002).

Correlações entre distribuição de espécies e variáveis ambientais - Para realizar análise global das correlações entre a distribuição das abundâncias das espécies e variáveis ambientais na área amostral, foi utilizada análise correspondência canônica (CCA) (ter Braak 1987) com o programa PC-ORD for Windows versão 4.14 (McCune \& Mefford 1999). A CCA requer duas matrizes de trabalho: a matriz das espécies e a matriz de variáveis ambientais. A matriz de abundâncias das espécies foi constituída do número de indivíduos por parcela das 50 espécies que apresentaram 30 ou mais indivíduos na amostra total. De acordo com as recomendações de ter Braak (1995), os valores de abundância foram transformados pela expressão $\log _{10}(a+1)$ para compensar os desvios causados por alguns poucos valores muito elevados. A matriz das variáveis ambientais incluiu inicialmente todas as variáveis químicas e texturais do solo, as três variáveis topográficas, as classes de drenagem e o fator borda. Após processar uma CCA preliminar, foram eliminadas as variáveis redundantes ou que apresentaram baixa correlação com os dois primeiros eixos de ordenação. As sete variáveis utilizadas pela CCA final foram: fator borda, cota média, classe de drenagem, $\mathrm{pH}, \mathrm{Al}, \mathrm{V}$ e matéria orgânica. Foi aplicado o teste de permutação de Monte Carlo para verificar a significância das correlações entre os padrões emergentes das espécies e variáveis ambientais na CCA final. As classes de solo foram discriminadas no diagrama de ordenação das parcelas para facilitar a interpretação ambiental $a$ posteriori dos padrões emergentes das espécies. 


\section{Resultados}

Composição florística - A lista de espécies arbóreas encontradas na floresta do Parque Ecológico Quedas do Rio Bonito é apresentada na Tabela 1. Todos os espécimes coletados foram identificados até o nível de espécie. No total, foram registradas 384 espécies, pertencentes a 182 gêneros e 68 famílias botânicas. Dentre elas, 171 espécies foram acrescentadas na listagem florística a partir das coletas realizadas fora das transecções. As famílias que contribuíram com maior riqueza de espécies foram Myrtaceae, com 52 espécies, Fabaceae, com 38, Melastomataceae, com 30, Lauraceae, com 26, e Asteraceae, com 15. Essas cinco famílias somaram $41,4 \%$ do total das espécies. Por outro lado, 20 famílias (28,57\%) foram amostradas por uma única espécie. É justo salientar que a presente listagem resulta do trabalho desenvolvido no PEQRB ao longo de mais de 20 anos por vários pesquisadores.

Tabela 1. Espécies arbóreas encontradas na floresta do PEQRB, Lavras, MG, organizadas por família e seguidas de seu número de registro (Nr) no Herbário ESAL (ou do coletor, quando precedido de PD, Paulo E. Dalanesi) e dos parâmetros quantitativos dos indivíduous amostrados em 80 parcelas de $10 \times 30 \mathrm{~m}$ : NI = número de indivíduos; $\mathrm{P}$ = número de parcelas com ocorrência da espécie; $\mathrm{AB}=$ área basal; VI = valor de importância; A = altura máxima. * Espécies registradas apenas no levantamento florístico.

\begin{tabular}{|c|c|c|c|c|c|c|}
\hline Famílias/Espécies & $\mathrm{Nr}$ & NI & $\mathrm{P}$ & $\mathrm{AB}\left(\mathrm{m}^{2}\right)$ & VI & $\mathrm{A}(\mathrm{m})$ \\
\hline \multicolumn{7}{|l|}{ ANACARDIACEAE } \\
\hline Lithraea molleoides (Vell.) Engler & $8311^{*}$ & - & - & - & - & - \\
\hline Tapirira guianensis Aublet & 16720 & 8 & 6 & 0,0296 & 0,53 & 9,5 \\
\hline T. obtusa (Benth.) Mitchell & 7870 & 190 & 68 & 29,9070 & 13,23 & 20,0 \\
\hline \multicolumn{7}{|l|}{ ANNONACEAE } \\
\hline Annona cacans Warm. & 12787 & 10 & 7 & 0,3667 & 1,24 & 20,0 \\
\hline Duguetia lanceolata A. St.-Hil. & 2227 & 10 & 8 & 0,6396 & 1,78 & 20,0 \\
\hline Guatteria australis A. St.-Hil. & 17060 & 6 & 6 & 0,0257 & 0,47 & 9,0 \\
\hline G. nigrescens Mart. & 15495 & 59 & 33 & 0,4777 & 3,85 & 15,0 \\
\hline Rollinia laurifolia Schltdl. & 16726 & 14 & 10 & 0,2000 & 1,17 & 14,0 \\
\hline R. sericea (R.E. Fries) R.E. Fries & 16727 & 20 & 15 & 0,1112 & 1,39 & 11,0 \\
\hline R. sylvatica (A. St.-Hil.) Mart. & 16728 & 2 & 2 & 0,0189 & 0,18 & 12,0 \\
\hline Xylopia brasiliensis Sprengel & 14391 & 14 & 12 & 0,1556 & 1,19 & 16,0 \\
\hline X. emarginata Mart. & $12647 *$ & - & - & - & - & - \\
\hline \multicolumn{7}{|l|}{ APOCYNACEAE } \\
\hline Aspidosperma cylindrocarpon Müll. Arg. & 16730 & 1 & 1 & 0,0287 & 0,12 & 14,0 \\
\hline A. parvifolium A. DC. & 16731 & 30 & 25 & 0,5562 & 2,91 & 18,0 \\
\hline A. spruceanum Benth. & 16733 & 5 & 4 & 0,1067 & 0,50 & 15,0 \\
\hline Tabernaemontana catharinensis A. DC. & PD-16* & - & - & - & - & - \\
\hline \multicolumn{7}{|l|}{ AQUIFOLIACEAE } \\
\hline Ilex affinis Gardner & $10900 *$ & - & - & - & - & - \\
\hline I. amara (Vell.) Loes. & 16225 & 12 & 11 & 0,0792 & 0,95 & 13,0 \\
\hline I. brasiliensis (Sprengel) Loes. & $8921 *$ & - & - & - & - & - \\
\hline I. brevicuspis Reissek & 12834 & 13 & 10 & 0,2113 & 1,17 & 18,0 \\
\hline I. cerasifolia Reissek & 16852 & 12 & 7 & 0,0786 & 0,76 & 10,0 \\
\hline I. conocarpa Reissek & 11947 & 5 & 4 & 0,0474 & 0,40 & 9,0 \\
\hline I. paraguariensis A. St.-Hil. & 16226 & 17 & 6 & 0,2169 & 1,09 & 12,0 \\
\hline I. sapotifolia Reissek & 12840 & 4 & 4 & 0,0406 & 0,36 & 13,0 \\
\hline I. theezans Mart. & $16227 *$ & - & - & - & - & - \\
\hline \multicolumn{7}{|l|}{ ARALIACEAE } \\
\hline Dendropanax cuneatus (DC.) Decne \& Planchon & 9715 & 2 & 2 & 0,0061 & 0,15 & 8,0 \\
\hline Schefflera angustissima (E. Marchal) D. Frodin & 16712 & 1 & 1 & 0,0424 & 0,15 & 12,0 \\
\hline S. calva (Cham.) D. Frodin & 12797 & 29 & 17 & 0,4882 & 2,39 & 18,0 \\
\hline S. macrocarpa (Cham. \& Schltdl.) D. Frodin & $16735^{*}$ & - & - & - & - & - \\
\hline S. vinosa (Cham. \& Schltdl.) D. Frodin & $16383 *$ & - & - & - & - & - \\
\hline \multicolumn{7}{|l|}{ ARAUCARIACEAE } \\
\hline Araucaria angustifolia (Bert.) Kuntze & $16384 *$ & - & - & - & - & - \\
\hline \multicolumn{7}{|l|}{ ARECACEAE } \\
\hline Geonoma schottiana Mart. & 16385 & 30 & 19 & 0,0857 & 1,78 & 10,0 \\
\hline Syagrus flexuosa (Mart.) Becc. & 3268 & 1 & 1 & 0,0161 & 0,10 & 2,5 \\
\hline S. romanzoffiana (Cham.) Glassman & $16903^{*}$ & - & - & - & - & - \\
\hline
\end{tabular}


Tabela 1 (continuação)

\begin{tabular}{|c|c|c|c|c|c|c|}
\hline Famílias/Espécies & $\mathrm{Nr}$ & NI & $\mathrm{P}$ & $\mathrm{AB}\left(\mathrm{m}^{2}\right)$ & VI & $\mathrm{A}(\mathrm{m})$ \\
\hline \multicolumn{7}{|l|}{ ASTERACEAE } \\
\hline Austrocritonia velutina (Gardner) King \& Rob. & $\mathrm{PD}-1^{*}$ & - & - & - & - & - \\
\hline Austroeupatorium inulaefolium (Kunth) King \& Rob. & $17069 *$ & - & - & - & - & - \\
\hline Baccharis brachylaenoides DC. & 2883 & 1 & 1 & 0,0029 & 0,08 & 4,5 \\
\hline Dasyphyllum brasiliense (Sprengel) Cabrera & 4866* & - & - & - & - & - \\
\hline Eremanthus erythropappus (DC.) MacLeish & 16740 & 70 & 12 & 12,8500 & 4,59 & 19,0 \\
\hline E. glomerulatus Less. & $4494 *$ & - & - & - & - & - \\
\hline E. incanus (Less.) Less. & 12805 & 3 & 3 & 0,0687 & 0,34 & 12,0 \\
\hline E. polycephalus (DC.) MacLeish & $8506 *$ & - & - & - & - & - \\
\hline Gochnatia paniculata (Less.) Cabrera & $17070 *$ & - & - & - & - & - \\
\hline G. polymorpha (Less.) Cabrera & $16420 *$ & - & - & - & - & - \\
\hline Piptocarpha axillaris (Less.) Baker & $12803 *$ & - & - & - & - & - \\
\hline P. macropoda Baker & 16744 & 9 & 9 & 0,2383 & 1,07 & 13,0 \\
\hline Vernonanthura diffusa (Less.) H. Robinson & 16745 & 1 & 1 & 0,0250 & 0,12 & 12,0 \\
\hline V. discolor (Less.) H. Robinson & $17250 *$ & - & - & - & - & - \\
\hline V. phosphorica (Vell.) H. Robinson & $16746 *$ & - & - & - & - & - \\
\hline \multicolumn{7}{|l|}{ BIGNONIACEAE } \\
\hline Jacaranda macrantha Cham. & 12796 & 30 & 20 & 0,4235 & 2,44 & 15,0 \\
\hline J. subalpina W. Morawetz & $\mathrm{PD}-2^{*}$ & - & - & - & - & - \\
\hline Tabebuia chrysotricha (Mart.) Standley & $16751 *$ & - & - & - & - & - \\
\hline T. ochracea (Cham.) Rizz. & $8625^{*}$ & - & - & - & - & - \\
\hline T. serratifolia (Vahl) Nichols & 16302 & 2 & 1 & 0,0228 & 0,14 & 7,0 \\
\hline T. vellosoi Toledo & $17252 *$ & - & - & - & - & - \\
\hline \multicolumn{7}{|l|}{ BORAGINACEAE } \\
\hline Cordia ecalyculata Vell. & 14820 & 1 & 1 & 0,0025 & 0,08 & 6,0 \\
\hline C. sellowiana Cham. & 16755 & 30 & 19 & 0,5072 & 2,54 & 14,0 \\
\hline \multicolumn{7}{|l|}{ BURSERACEAE } \\
\hline Protium heptaphyllum (Aublet) Marchand & $16758 *$ & - & - & - & - & - \\
\hline P. spruceanum (Benth.) Engler & 16399 & 20 & 12 & 0,1391 & 1,30 & 12,0 \\
\hline P. widgrenii Engler & 12607 & 100 & 33 & 0,9439 & 5,69 & 14,0 \\
\hline \multicolumn{7}{|l|}{ CANELLACEAE } \\
\hline Cinnamodendron dinisii Schwacke & $17084^{*}$ & - & - & - & - & - \\
\hline \multicolumn{7}{|l|}{ CANNABACEAE } \\
\hline Celtis iguanaea (Jacquin) Sargent & $16940 *$ & - & - & - & - & - \\
\hline C. pubescens Sprengel & $17001 *$ & - & - & - & - & - \\
\hline Trema micrantha (L.) Blume & $13181^{*}$ & - & - & - & - & - \\
\hline \multicolumn{7}{|l|}{ CELASTRACEAE } \\
\hline Austroplenckia populnea (Reissek) Lundell & $7721 *$ & - & - & - & - & - \\
\hline Maytenus glazioviana Loes. & 16762 & 27 & 14 & 0,3563 & 1,96 & 12,0 \\
\hline M. salicifolia Reissek & 12807 & 25 & 18 & 0,1936 & 1,80 & 14,0 \\
\hline Salacia elliptica (Mart.) G. Don & 12842 & 45 & 28 & 0,3428 & 3,03 & 10,0 \\
\hline \multicolumn{7}{|l|}{ CHRYSOBALANACEAE } \\
\hline Hirtella hebeclada Moric. & 16408 & 1 & 1 & 0,0092 & 0,09 & 7,0 \\
\hline \multicolumn{7}{|l|}{ CLETHRACEAE } \\
\hline Clethra scabra Pers. & 12794 & 30 & 14 & 0,4170 & 2,14 & 10,0 \\
\hline \multicolumn{7}{|l|}{ CLUSIACEAE } \\
\hline Calophyllum brasiliense Cambess. & 12814 & 4 & 3 & 0,0281 & 0,29 & 10,0 \\
\hline Garcinia gardneriana (Planchon \& Triana) Zappi & 16454 & 6 & 6 & 0,0727 & 0,56 & 11,0 \\
\hline Kielmeyera coriacea (Sprengel) Mart. & $6734 *$ & - & - & - & - & - \\
\hline K. lathrophyton Saddi & 14889 & 1 & 1 & 0,0026 & 0,08 & 7,0 \\
\hline Vismia brasiliensis Choisy & 9898 & 37 & 20 & 0,5440 & 2,83 & 15,0 \\
\hline V. parviflora Cham. \& Schltdl. & $16057 *$ & - & - & - & - & - \\
\hline \multicolumn{7}{|l|}{ COMBRETACEAE } \\
\hline Terminalia glabrescens Mart. & 9601 & 4 & 4 & 0,0433 & 0,36 & 12,0 \\
\hline T. januariensis DC. & 12806 & 2 & 2 & 0,0243 & 0,19 & 12,0 \\
\hline \multicolumn{7}{|l|}{ CONNARACEAE } \\
\hline Connarus regnellii G. Schellenb. & 16768 & 15 & 10 & 0,0963 & 1,01 & $\begin{array}{c}10,0 \\
\text { continua }\end{array}$ \\
\hline
\end{tabular}


Tabela 1 (continuação)

\begin{tabular}{|c|c|c|c|c|c|c|}
\hline Famílias/Espécies & $\mathrm{Nr}$ & NI & $\mathrm{P}$ & $\mathrm{AB}\left(\mathrm{m}^{2}\right)$ & VI & $A(m)$ \\
\hline \multicolumn{7}{|l|}{ CUNONIACEAE } \\
\hline Lamanonia ternata Vell. & 9703 & 2 & 2 & 0,0463 & 0,23 & 11,0 \\
\hline \multicolumn{7}{|l|}{ CYATHEACEAE } \\
\hline Alsophila sternbergii (Sternb.) Conant & 12810 & 10 & 4 & 0,0921 & 0,60 & 7,5 \\
\hline Cyathea corcovadensis (Raddi) Domin & 14886 & 6 & 3 & 0,0620 & 0,40 & 5,0 \\
\hline C. delgadii Sternb. & 8769 & 9 & 5 & 0,1135 & 0,66 & 9,0 \\
\hline C. phalerata Mart. & 12811 & 14 & 7 & 0,1397 & 0,92 & 7,0 \\
\hline C. rufa (Fée) Lellinger & PD-7 & 3 & 1 & 0,0488 & 0,21 & 5,5 \\
\hline Sphaeropteris gardneri (Hooker) Tryon & 17264 & 2 & 2 & 0,0134 & 0,17 & 5,0 \\
\hline \multicolumn{7}{|l|}{ ELAEOCARPACEAE } \\
\hline Sloanea monosperma Vell. & 12804 & 9 & 8 & 0,1225 & 0,82 & 17,0 \\
\hline \multicolumn{7}{|l|}{ ERYTHROXYLACEAE } \\
\hline Erythroxylum amplifolium (Mart.) O.E. Schulz & PD-8* & - & - & - & - & - \\
\hline E. cuneifolium (Mart.) O.E. Schulz & $11237 *$ & - & - & - & - & - \\
\hline E. deciduum A. St.-Hil. & $11231 *$ & - & - & - & - & - \\
\hline E. pelleterianum A. St.-Hil. & PD-9* & - & - & - & - & - \\
\hline E. pulchrum A. St.-Hil. & PD-10* & - & - & - & - & - \\
\hline \multicolumn{7}{|l|}{ EUPHORBIACEAE } \\
\hline Actinostemon klotzschii (Didrichs) Pax & $16435 *$ & - & - & - & - & - \\
\hline Alchornea glandulosa Poepp. \& Endl. & $16783 *$ & - & - & - & - & - \\
\hline A. triplinervia (Sprengel) Müll. Arg. & 12814 & 70 & 39 & 16,0430 & 6,45 & 18,0 \\
\hline Croton floribundus Sprengel & 12812 & 46 & 31 & 0,8087 & 4,04 & 16,0 \\
\hline C. urucurana Baillon & $13191 *$ & - & - & - & - & - \\
\hline C. verrucosus Radcl.-Sm. \& Govaerts & 12813 & 71 & 35 & 15,5660 & 6,19 & 22,0 \\
\hline Gymnanthes concolor (Sprengel) Müll. Arg. & 12815 & 86 & 34 & 0,5769 & 4,73 & 10,0 \\
\hline Manihot grahamii Pohl & $17102 *$ & - & - & - & - & - \\
\hline Pera glabrata (Schott) Poepp. & 11963 & 91 & 33 & 18,0560 & 7,04 & 19,0 \\
\hline Sapium glandulosum (L.) Morong & 16787 & 2 & 2 & 0,0704 & 0,27 & 15,0 \\
\hline \multicolumn{7}{|l|}{ FABACEAE-CAESALPINIOIDEAE } \\
\hline Cassia ferruginea (Schrad.) Schrad. & 12862 & 2 & 2 & 0,0260 & 0,19 & 10,0 \\
\hline Copaifera langsdorffii Desf. & 12861 & 154 & 35 & 19,1860 & 8,86 & 16,0 \\
\hline Sclerolobium rugosum Mart. & 12859 & 56 & 32 & 42,6270 & 10,61 & 25,0 \\
\hline Senna macranthera (Vell.) Irwin \& Barneby & 11558* & - & - & - & - & - \\
\hline \multicolumn{7}{|l|}{ FABACEAE-FABOIDEAE } \\
\hline Acosmium dasycarpum (Vogel) Yakovlev & $6169 *$ & - & - & - & - & - \\
\hline Andira fraxinifolia Benth. & $16834 *$ & - & - & - & - & - \\
\hline A. ormosioides Benth. & PD-19* & - & - & - & - & - \\
\hline Bowdichia virgilioides Kunth & 8697* & - & - & - & - & - \\
\hline Dalbergia frutescens (Vell.) Britton & 12872 & 5 & 5 & 0,2035 & 0,73 & 12 \\
\hline D. miscolobium Benth. & $13927 *$ & - & - & - & - & - \\
\hline D. villosa (Benth.) Benth. & 12856 & 10 & 8 & 0,0985 & 0,80 & 12,0 \\
\hline Erythrina falcata Benth. & 16514 & 1 & 1 & 0,0118 & 0,09 & 8,0 \\
\hline Machaerium amplum Benth. & 15741 & 1 & 1 & 0,0350 & 0,13 & 10,0 \\
\hline M. brasiliense Vogel & 12873 & 9 & 4 & 0,0539 & 0,50 & 11,0 \\
\hline M. hirtum (Vell.) Stellfeld & $16847 *$ & - & - & - & - & - \\
\hline M. nictitans (Vell.) Benth. & 16846 & 10 & 9 & 0,4677 & 1,52 & 18,0 \\
\hline M. stipitatum (DC.) Vogel & $16845^{*}$ & - & - & - & - & - \\
\hline M. villosum Vogel & 11532 & 35 & 23 & 0,8297 & 3,44 & 16,0 \\
\hline Myrocarpus frondosus Fr. Allem. & $14841 *$ & - & - & - & - & - \\
\hline Myroxylon peruiferum L.f. & 16521 & 3 & 3 & 0,0067 & 0,23 & 8,0 \\
\hline Ormosia arborea (Vell.) Harms & 12223 & 1 & 1 & 0,0268 & 0,12 & 11,0 \\
\hline Platycyamus regnellii Benth. & 16524 & 4 & 3 & 0,0371 & 0,31 & 10,0 \\
\hline Platypodium elegans Vogel & 16523* & - & - & - & - & - \\
\hline \multicolumn{7}{|l|}{ FABACEAE-MIMOSOIDEAE } \\
\hline Acacia polyphylla DC. & 16823 & 1 & 1 & 0,0176 & 0,10 & 7,0 \\
\hline
\end{tabular}

Tabela 1 (continuação) 


\begin{tabular}{|c|c|c|c|c|c|c|}
\hline Famílias/Espécies & $\mathrm{Nr}$ & NI & $\mathrm{P}$ & $\mathrm{AB}\left(\mathrm{m}^{2}\right)$ & VI & $\mathrm{A}(\mathrm{m})$ \\
\hline \multicolumn{7}{|l|}{ FABACEAE-MIMOSOIDEAE } \\
\hline Albizia polycephala (Benth.) Killip & $17014^{*}$ & - & - & - & - & - \\
\hline Anadenanthera colubrina (Vell.) Brenan & $13242 *$ & - & - & - & - & - \\
\hline Enterolobium contortisiliquum (Vell.) Morong & $15927 *$ & - & - & - & - & - \\
\hline Inga ingoides (Rich.) Willd. & 5341 & 2 & 1 & 0,0139 & 0,12 & 10,0 \\
\hline I. laurina (Swartz) Willd. & $15733^{*}$ & - & - & - & - & - \\
\hline I. marginata Willd. & 13236 & 1 & 1 & 0,0054 & 0,08 & 7,0 \\
\hline I. sessilis (Vell.) Mart. & 15466 & 1 & 1 & 0,0040 & 0,08 & 8,0 \\
\hline I. striata Benth. & 12867 & 8 & 6 & 0,1495 & 0,75 & 16,0 \\
\hline I. vera Willd. & 16504 & 1 & 1 & 0,0051 & 0,08 & 18,0 \\
\hline I. vulpina Mart. & 13238* & - & - & - & - & - \\
\hline Leucochloron incuriale (Vell.) Barneby \& Grimes & 16253 & 26 & 14 & 0,3158 & 1,86 & 16,0 \\
\hline Piptadenia gonoacantha (Mart.) Macbr. & 13460 & 12 & 8 & 0,2544 & 1,13 & 11,0 \\
\hline Pseudopiptadenia leptostachya (Benth.) Rausch. & 12863 & 5 & 4 & 0,1009 & 0,49 & 12,0 \\
\hline Stryphnodendron adstringens (Mart.) Cov. & $8696 *$ & - & - & - & - & - \\
\hline \multicolumn{7}{|l|}{ HUMIRIACEAE } \\
\hline \multicolumn{7}{|l|}{ ICACINACEAE } \\
\hline Citronella paniculata (Mart.) Howard & 16457 & 1 & 1 & 0,0042 & 0,08 & 5,0 \\
\hline \multicolumn{7}{|l|}{ LACISTEMATACEAE } \\
\hline Lacistema hasslerianum Chodat & 16460 & 2 & 2 & 0,0079 & 0,16 & 7,0 \\
\hline \multicolumn{7}{|l|}{ LAMIACEAE } \\
\hline Aegiphila lhotskiana Cham. & $16943^{*}$ & - & - & - & - & - \\
\hline A. sellowiana Cham. & $16944^{*}$ & - & - & - & - & - \\
\hline Vitex cymosa Bert. & 16623 & 6 & 5 & 0,0840 & 0,53 & 15,0 \\
\hline V. polygama Cham. & 12974 & 7 & 6 & 0,0743 & 0,59 & 11,0 \\
\hline \multicolumn{7}{|l|}{ LAURACEAE } \\
\hline Aiouea costaricensis (Mez) Kosterm. & 12123 & 1 & 1 & 0,0021 & 0,08 & 10,0 \\
\hline Aniba firmula (Nees \& Mart.) Mez & 12211 & 1 & 1 & 0,0140 & 0,10 & 10,0 \\
\hline Cinnamomum glaziovii (Mez) Vattimo & 12847 & 2 & 2 & 0,0077 & 0,16 & 6,5 \\
\hline Cryptocarya aschersoniana $\mathrm{Mez}$ & 16804 & 31 & 20 & 0,6331 & 2,84 & 20,0 \\
\hline C. moschata Nees \& Mart. & PD-5* & - & - & - & - & - \\
\hline Endlicheria paniculata (Sprengel) Macbr. & 16805 & 1 & 1 & 0,0022 & 0,08 & 7,0 \\
\hline Nectandra cissiflora Nees & 12848 & 6 & 6 & 0,0510 & 0,52 & 12,0 \\
\hline N. grandiflora Nees & 12849 & 12 & 9 & 0,0765 & 0,85 & 15,0 \\
\hline N. lanceolata Nees & $12853 *$ & - & - & - & - & - \\
\hline N. megapotamica (Sprengel) Mez & 16808 & 1 & 1 & 0,0046 & 0,08 & 8,0 \\
\hline N. nitidula Nees & $16809 *$ & - & - & - & - & - \\
\hline N. oppositifolia Nees & 12845 & 34 & 26 & 0,4252 & 2,82 & 15,0 \\
\hline Ocotea aciphylla (Nees) Mez & 12855 & 33 & 14 & 0,4294 & 2,24 & 18,0 \\
\hline O. acutifolia (Nees) Mez & $13024^{*}$ & - & - & - & - & - \\
\hline O. corymbosa (Meisner) Mez & 12854 & 46 & 31 & 0,8703 & 4,15 & 22,0 \\
\hline O. diospyrifolia (Meisner) Mez & 1865 & 5 & 5 & 0,4090 & 1,10 & 16,0 \\
\hline O. elegans Mez & 16135 & 5 & 4 & 0,0313 & 0,37 & 11,0 \\
\hline O. indecora (Schott) Mez & 16525 & 2 & 1 & 0,0137 & 0,12 & 8,0 \\
\hline O. minarum (Nees \& Mart.) Mez & $17384^{*}$ & - & - & - & - & - \\
\hline O. odorifera (Vell.) Rohwer & 12851 & 32 & 20 & 0,3903 & 2,43 & 15,0 \\
\hline O. puberula (Rich.) Nees & 17386 & 1 & 1 & 0,0331 & 0,13 & 11,0 \\
\hline O. pulchella Mart. & 12849 & 7 & 6 & 0,1068 & 0,65 & 15,0 \\
\hline O. spixiana (Nees) Mez & PD-14* & - & - & - & - & - \\
\hline O. variabilis (Nees) Mez & $16811^{*}$ & - & - & - & - & - \\
\hline O. velutina (Nees) Rohwer & 16812 & 1 & 1 & 0,0207 & 0,11 & 12,0 \\
\hline Persea pyrifolia Nees \& Mart. & 12850 & 12 & 12 & 0,3797 & 1,55 & 18,0 \\
\hline \multicolumn{7}{|l|}{ LECYTHIDACEAE } \\
\hline Cariniana estrellensis (Raddi) Kuntze & $15824 *$ & - & - & - & - & - \\
\hline C. legalis (Mart.) Kuntze & $17013^{*}$ & - & - & - & - & - \\
\hline \multicolumn{7}{|l|}{ LYTHRACEAE } \\
\hline Lafoensia densiflora Pohl & 16254 & 3 & 3 & 0,0272 & 0,26 & 9,5 \\
\hline L. pacari A. St.-Hil. & 16464 & 3 & 3 & 0,2686 & 0,70 & 11,0 \\
\hline
\end{tabular}




\begin{tabular}{|c|c|c|c|c|c|c|}
\hline Famílias/Espécies & $\mathrm{Nr}$ & NI & $\mathrm{P}$ & $\mathrm{AB}\left(\mathrm{m}^{2}\right)$ & VI & $A(m)$ \\
\hline \multicolumn{7}{|l|}{ MAGNOLIACEAE } \\
\hline Talauma ovata A. St.-Hil. & 16842 & 2 & 2 & 0,1182 & 0,36 & 20,0 \\
\hline \multicolumn{7}{|l|}{ MALPIGHIACEAE } \\
\hline Byrsonima laxiflora Griseb. & 9767 & 34 & 28 & 10,554 & 4,06 & 17,0 \\
\hline Heteropterys byrsonimifolia A. Juss. & 8662 & 7 & 7 & 0,0931 & 0,67 & 12,0 \\
\hline \multicolumn{7}{|l|}{ MALVACEAE } \\
\hline Guazuma ulmifolia Lam. & $16609 *$ & - & - & - & - & - \\
\hline Helicteres ovata Lam. & $9670 *$ & - & - & - & - & - \\
\hline Luehea divaricata Mart. \& Zucc. & $16616^{*}$ & - & - & - & - & - \\
\hline L. grandiflora Mart. \& Zucc. & 9462 & 3 & 2 & 0,0325 & 0,23 & 10,0 \\
\hline L. paniculata Mart. & $1759 *$ & - & - & - & - & - \\
\hline \multicolumn{7}{|l|}{ MELASTOMATACEAE } \\
\hline Leandra glabrata (Bunbury) Cogn. & $9931 *$ & - & - & - & - & - \\
\hline L. lacunosa Cogn. & $13305 *$ & - & - & - & - & - \\
\hline L. pectinata Cogn. & $9913^{*}$ & - & - & - & - & - \\
\hline L. scabra DC. & 9900 & 4 & 3 & 0,0106 & 0,26 & 5,0 \\
\hline L. sericea DC. & 16049* & - & - & - & - & - \\
\hline L. sublanata Cogn. & $9905^{*}$ & - & - & - & - & - \\
\hline Miconia argyrophylla DC. & 9903 & 20 & 9 & 0,1502 & 1,18 & 16,0 \\
\hline M. brunnea Mart. & $13077 *$ & - & - & - & - & - \\
\hline M. chamissois Naudin & $11637 *$ & - & - & - & - & - \\
\hline M. chartacea Triana & 11998 & 64 & 26 & 0,4341 & 3,56 & 15,0 \\
\hline M. cinerascens Miq. & 17306* & - & - & - & - & - \\
\hline M. cinnamomifolia (DC.) Naudin & 12880 & 50 & 24 & 0,6996 & 3,61 & 20,0 \\
\hline M. corallina Sprengel & $16051 *$ & - & - & - & - & - \\
\hline M. inconspicua Miq. & $\mathrm{PD}-12 *$ & - & - & - & - & - \\
\hline M. latecrenata (DC.) Naudin & $15443 *$ & - & - & - & - & - \\
\hline M. ligustroides (DC.) Naudin & $11882 *$ & - & - & - & - & - \\
\hline M. minutiflora (Bonpl.) Triana & $6181^{*}$ & - & - & - & - & - \\
\hline M. paulensis Naudin & PD-13* & - & - & - & - & - \\
\hline M. pepericarpa DC. & $9918 *$ & - & - & - & - & - \\
\hline M. pusilliflora (DC.) Triana & $17311^{*}$ & - & - & - & - & - \\
\hline M. sellowiana Naudin & 16256 & 9 & 4 & 0,0642 & 0,52 & 9,0 \\
\hline M. theaezans (Bonpl.) Cogn & $9802 *$ & - & - & - & - & - \\
\hline M. trianae Cogn. & 8771 & 129 & 35 & 10,4210 & 6,66 & 20,0 \\
\hline Tibouchina adenostemon (DC.) Cogn. & 13229* & - & - & - & - & - \\
\hline T. candolleana (DC.) Cogn. & $7869 *$ & - & - & - & - & - \\
\hline T. fothergillae (DC.) Cogn. & PD-17* & - & - & - & - & - \\
\hline T. moricandiana (DC.) Baillon & 10663* & - & - & - & - & - \\
\hline T. sellowiana (Cham.) Cogn. & $940^{*}$ & - & - & - & - & - \\
\hline T. stenocarpa (DC.) Cogn. & 10598 & 8 & 6 & 0,1028 & 0,66 & 14,0 \\
\hline Trembleya parviflora (D. Don) Cogn. & 13340* & - & - & - & - & - \\
\hline \multicolumn{7}{|l|}{ MELIACEAE } \\
\hline Cabralea canjerana (Vell.) Mart. & 9627 & 25 & 19 & 0,2605 & 1,97 & 19,0 \\
\hline Cedrela fissilis Vell. & 16860 & 3 & 3 & 0,1422 & 0,47 & 10,0 \\
\hline Guarea macrophylla Vahl. & $12233 *$ & - & - & - & - & - \\
\hline Trichilia emarginata (Turcz.) C. DC. & 13079 & 11 & 4 & 0,1515 & 0,73 & 12,0 \\
\hline T. pallida Swartz & 16863 & 4 & 2 & 0,0211 & 0,23 & 7,0 \\
\hline \multicolumn{7}{|l|}{ MONIMIACEAE } \\
\hline Mollinedia argyrogyna Perkins & 15703 & 34 & 19 & 0,2638 & 2,20 & 10,0 \\
\hline M. triflora (Sprengel) Tul. & $9772 *$ & - & - & - & - & - \\
\hline \multicolumn{7}{|l|}{ MORACEAE } \\
\hline Ficus mexiae Standley & 12900 & 3 & 3 & 0,2004 & 0,58 & 20,0 \\
\hline Naucleopsis oblongifolia (Kuhlman) Carauta & 12899 & 5 & 4 & 0,0493 & 0,40 & 12,0 \\
\hline Sorocea bonplandii (Baillon) W. Burger & 16870 & 2 & 2 & 0,0076 & 0,16 & 7,0 \\
\hline \multicolumn{7}{|l|}{ MYRSINACEAE } \\
\hline Cybianthus brasiliensis (Mez) Agostini & $12897 *$ & - & - & - & - & - \\
\hline
\end{tabular}




\begin{tabular}{|c|c|c|c|c|c|c|}
\hline Famílias/Espécies & $\mathrm{Nr}$ & NI & $\mathrm{P}$ & $\mathrm{AB}\left(\mathrm{m}^{2}\right)$ & VI & $A(m)$ \\
\hline \multicolumn{7}{|l|}{ MYRSINACEAE } \\
\hline Cybianthus cuneifolius Mart. & $12458 *$ & - & - & - & - & - \\
\hline Myrsine coriacea (Swartz) R. Br. & $13530 *$ & - & - & - & - & - \\
\hline M. gardneriana A. DC. & 17322 & 12 & 10 & 0,0666 & 0,88 & 13,0 \\
\hline M. guianensis (Aublet) Kuntze & 13529 & 1 & 1 & 0,0042 & 0,08 & 9,0 \\
\hline M. lancifolia Mart. & $17323^{*}$ & - & - & - & - & - \\
\hline M. umbellata Mart. & 11533 & 77 & 38 & 0,4672 & 4,50 & 13,0 \\
\hline \multicolumn{7}{|l|}{ MYRTACEAE } \\
\hline Blepharocalyx salicifolius (Kunth) O. Berg & 8594 & 41 & 26 & 0,3692 & 2,89 & 15,0 \\
\hline Calycorectes acutatus (Miq.) Toledo & 16465 & 47 & 14 & 0,4697 & 2,65 & 12,0 \\
\hline Calyptranthes brasiliensis Sprengel & 9702 & 24 & 12 & 0,1009 & 1,33 & 12,0 \\
\hline C. clusiifolia (Miq.) O. Berg & 12927 & 37 & 24 & 0,4254 & 2,80 & 14,0 \\
\hline C. lucida Mart. & $1874 *$ & - & - & - & - & - \\
\hline Campomanesia guazumifolia (Cambess.) O. Berg & 16877 & 2 & 2 & 0,0246 & 0,19 & 9,0 \\
\hline C. pubescens (DC.) O. Berg & $7804 *$ & - & - & - & - & - \\
\hline C. rufa (O. Berg) Nied. & $12981 *$ & - & - & - & - & - \\
\hline C. velutina (Cambess.) O. Berg & $16879 *$ & - & - & - & - & - \\
\hline C. xanthocarpa O. Berg & $16880 *$ & - & - & - & - & - \\
\hline Eugenia blastantha (O. Berg) D. Legrand & PD-11* & - & - & - & - & - \\
\hline E. excelsa O. Berg & 12513 & 1 & 1 & 0,0026 & 0,08 & 6,0 \\
\hline E. florida DC. & 12925 & 1 & 1 & 0,0041 & 0,08 & 7,5 \\
\hline E. handroana D. Legrand & 9673 & 14 & 11 & 0,1266 & 1,09 & 12,0 \\
\hline E. hyemalis Cambess. & 12924 & 54 & 29 & 0,5453 & 3,66 & 12,0 \\
\hline E. neomyrtifolia Sobral & 16881 & 1 & 1 & 0,0127 & 0,09 & 12,0 \\
\hline E. pitanga (O. Berg) Kiaersk. & $12934 *$ & - & - & - & - & - \\
\hline E. punicifolia (Kunth) DC. & $12084 *$ & - & - & - & - & - \\
\hline E. pyriformis Cambess. & $8918^{*}$ & - & - & - & - & - \\
\hline E. stictosepala Kiaersk. & $9831^{*}$ & - & - & - & - & - \\
\hline E. subavenia O. Berg & $15411^{*}$ & - & - & - & - & - \\
\hline Gomidesia affinis (Cambess.) D. Legrand & 12931 & 9 & 7 & 0,0483 & 0,64 & 10,0 \\
\hline G. anacardiifolia (Gardner) O. Berg & $9943 *$ & - & - & - & - & - \\
\hline G. eriocalyx (DC.) O. Berg & 7806 & 14 & 13 & 0,0819 & 1,10 & 10,0 \\
\hline G. fenzliana O. Berg & $9000^{*}$ & - & - & - & - & - \\
\hline G. gaudichaudiana O. Berg & $2806 *$ & - & - & - & - & - \\
\hline Marlierea racemosa (Vell.) Kiaersk. & 16468 & 3 & 2 & 0,0161 & 0,20 & 7,0 \\
\hline Myrceugenia ovata (Hooker \& Arnot) O. Berg & $12930 *$ & - & - & - & - & - \\
\hline Myrcia breviramis (O. Berg) D. Legrand & 16477 & 1 & 1 & 0,0046 & 0,08 & 6,0 \\
\hline M. crassifolia (Miq.) Kiaersk. & 8814 & 1 & 1 & 0,0032 & 0,08 & 5,5 \\
\hline M. eriopus DC. & 16275 & 1 & 1 & 0,0077 & 0,09 & 7,5 \\
\hline M. fallax (Rich.) DC. & 9624 & 66 & 25 & 0,3915 & 3,49 & 12,0 \\
\hline M. guianensis (Aublet) DC. & 5004 & 1 & 1 & 0,0020 & 0,08 & 5,5 \\
\hline M. laruotteana Cambess. & $16889 *$ & - & - & - & - & - \\
\hline M. rostrata DC. & 11242 & 40 & 25 & 0,3997 & 2,87 & 14,0 \\
\hline M. tomentosa (Aublet) DC. & 9017 & 11 & 9 & 0,1308 & 0,93 & 12,0 \\
\hline M. variabilis DC. & 6627 & 6 & 4 & 0,0354 & 0,40 & 6,0 \\
\hline M. velutina O. Berg & $9723 *$ & - & - & - & - & - \\
\hline M. venulosa DC. & 16893 & 24 & 17 & 0,2494 & 1,83 & 12,5 \\
\hline Myrciaria floribunda (West) O. Berg & 9862 & 8 & 7 & 0,0518 & 0,62 & 8,0 \\
\hline Pimenta pseudocaryophyllus (Gomes) Landrum & 12933 & 33 & 16 & 0,2069 & 1,93 & 11,0 \\
\hline Psidium cattleianum Sabine & 12503 & 5 & 5 & 0,0250 & 0,40 & 10,0 \\
\hline Plinia rivularis (Cambess.) Rotman & $9852 *$ & - & - & - & - & - \\
\hline Psidium cinereum Mart. & $9080 *$ & - & - & - & - & - \\
\hline P. guajava L. & $16897 *$ & - & - & - & - & - \\
\hline P. rufum Mart. & $16898 *$ & - & - & - & - & - \\
\hline P. sartorianum (O. Berg) Nied. & $12764 *$ & - & - & - & - & - \\
\hline Siphoneugena densiflora O. Berg & 12938 & 171 & 49 & 17,213 & 9,57 & 18,0 \\
\hline S. kiaerskoviana (Burret) Kausel & 12936 & 4 & 3 & 0,0620 & 0,35 & 10,0 \\
\hline
\end{tabular}




\begin{tabular}{|c|c|c|c|c|c|c|}
\hline Famílias/Espécies & $\mathrm{Nr}$ & NI & $\mathrm{P}$ & $\mathrm{AB}\left(\mathrm{m}^{2}\right)$ & VI & $A(m)$ \\
\hline \multicolumn{7}{|l|}{ MYRTACEAE } \\
\hline Siphoneugena kuhlmannii Mattos & 12939 & 2 & 2 & 0,0088 & 0,16 & 7,0 \\
\hline S. widgreniana O. Berg & 12500 & 6 & 4 & 0,0556 & 0,43 & 10,0 \\
\hline Syzygium jambos (L.) Alston & 2128 & 15 & 9 & 0,0733 & 0,92 & 13,0 \\
\hline \multicolumn{7}{|l|}{ NYCTAGINACEAE } \\
\hline Guapira graciliflora (Schmidt) Lundell & $3105^{*}$ & - & - & - & - & - \\
\hline G. hirsuta (Choisy) Lundell & $16900 *$ & - & - & - & - & - \\
\hline G. noxia (Netto) Lundell & $3176^{*}$ & - & - & - & - & - \\
\hline G. opposita (Vell.) Reitz & 16901 & 13 & 10 & 0,0722 & 0,92 & 8,0 \\
\hline \multicolumn{7}{|l|}{ OCHNACEAE } \\
\hline Ouratea semiserrata (Mart. \& Nees) Engler & $12541 *$ & - & - & - & - & - \\
\hline \multicolumn{7}{|l|}{ OLACACEAE } \\
\hline Heisteria silvianii Schwacke & 12947 & 20 & 16 & 0,1759 & 1,56 & 12,0 \\
\hline \multicolumn{7}{|l|}{ OLEACEAE } \\
\hline Chionanthus trichotomus (Vell.) P.S. Green & $14954 *$ & - & - & - & - & - \\
\hline \multicolumn{7}{|l|}{ OPILIACEAE } \\
\hline Agonandra excelsa Griseb. & 17037 & 3 & 3 & 0,0203 & 0,25 & 10,0 \\
\hline \multicolumn{7}{|l|}{ PHYLLANTHACEAE } \\
\hline Hyeronima ferruginea Müll. Arg. & 17102 & 7 & 5 & 0,0400 & 0,48 & 9,0 \\
\hline \multicolumn{7}{|l|}{ PICRAMNIACEAE } \\
\hline Picramnia ciliata Mart. & $16904 *$ & - & - & - & - & - \\
\hline P. glazioviana Engler & 12969 & 2 & 2 & 0,0063 & 0,15 & 6,0 \\
\hline P. parvifolia Engler & $15110 *$ & - & - & - & - & - \\
\hline \multicolumn{7}{|l|}{ PIPERACEAE } \\
\hline Piper aduncum L. & $14831^{*}$ & - & - & - & - & - \\
\hline P. caracolanum C. DC. & $12535 *$ & - & - & - & - & - \\
\hline P. cernuum Vell. & 13067 & 1 & 1 & 0,0024 & 0,08 & 5,0 \\
\hline P. gaudichaudianum Kunth & 9726* & - & - & - & - & - \\
\hline P. umbellatum L. & $12270^{*}$ & - & - & - & - & - \\
\hline \multicolumn{7}{|l|}{ PODOCARPACEAE } \\
\hline Podocarpus sellowii Klotzsch & $13123 *$ & - & - & - & - & - \\
\hline \multicolumn{7}{|l|}{ POLYGONACEAE } \\
\hline Coccoloba mollis Casar. & 16906 & 11 & 6 & 0,2097 & 0,93 & 15,0 \\
\hline C. warmingii Meisner & PD-4 & 70 & 34 & 13,0030 & 5,66 & 16,0 \\
\hline Ruprechtia laxiflora Meisner & $14950 *$ & - & - & - & - & - \\
\hline \multicolumn{7}{|l|}{ PROTEACEAE } \\
\hline Euplassa legalis (Vell.) Johnston & 9861 & 1 & 1 & 0,0022 & 0,08 & 6,5 \\
\hline E. organensis (Gardner) Johnston & 12961 & 3 & 2 & 0,0276 & 0,22 & 14,0 \\
\hline Roupala brasiliensis Klotzsch & $16908^{*}$ & - & - & - & - & - \\
\hline R. montana Aublet & 8786* & - & - & - & - & - \\
\hline R. rhombifolia Mart. & 12940 & 13 & 9 & 0,3040 & 1,29 & 12,0 \\
\hline \multicolumn{7}{|l|}{ PUTRANJIVACEAE } \\
\hline Drypetes sessiliflora Fr. Allem. & 12835 & 3 & 3 & 0,0225 & 0,25 & 11,0 \\
\hline \multicolumn{7}{|l|}{ ROSACEAE } \\
\hline Prunus brasiliensis (Cham. \& Schltdl.) D. Dietr. & 16910 & 2 & 2 & 0,0218 & 0,18 & 10,0 \\
\hline P. myrtifolia (L.) Urban & 16574 & 53 & 30 & 0,7596 & 4,08 & 14,0 \\
\hline P. sellowii Koehne & $16575 *$ & - & - & - & - & - \\
\hline \multicolumn{7}{|l|}{ RUBIACEAE } \\
\hline Alibertia concolor (Cham.) K. Schum. & 8768 & 6 & 6 & 0,0268 & 0,48 & 8,5 \\
\hline A. elliptica (Cham.) K. Schum. & $12956 *$ & - & - & - & - & - \\
\hline A. sessilis (Vell.) K. Schum. & $3989 *$ & - & - & - & - & - \\
\hline Alseis floribunda Schott & PD-3* & - & - & - & - & - \\
\hline Amaioua guianensis Aublet & 12955 & 134 & 26 & 0,7528 & 5,83 & 13,0 \\
\hline Bathysa australis (A. St.-Hil.) Benth. \& Hook. f. & 12951 & 5 & 2 & 0,0455 & 0,30 & 12,0 \\
\hline Chomelia sericea Müll. Arg. & $12558 *$ & - & - & - & - & - \\
\hline Coutarea hexandra (Jacquin) K. Schum. & $16579 *$ & - & - & - & - & - \\
\hline Faramea cyanea Müll. Arg. & 8799 & 68 & 27 & 0,7316 & 4,25 & 10,0 \\
\hline
\end{tabular}




\begin{tabular}{|c|c|c|c|c|c|c|}
\hline Famílias/Espécies & $\mathrm{Nr}$ & NI & $\mathrm{P}$ & $\mathrm{AB}\left(\mathrm{m}^{2}\right)$ & VI & $\mathrm{A}(\mathrm{m})$ \\
\hline \multicolumn{7}{|l|}{ RUBIACEAE } \\
\hline Faramea multiflora A. Rich. & 12953 & 4 & 4 & 0,0222 & 0,33 & 12,0 \\
\hline Guettarda uruguensis Cham. \& Schltdl. & $13247^{*}$ & - & - & - & - & - \\
\hline Ixora warmingii Müll. Arg. & 12552 & 31 & 12 & 0,2149 & 1,71 & 14,5 \\
\hline Posoqueria latifolia (Rudge) Roem. \& Schultz & $13227 *$ & - & - & - & - & - \\
\hline Psychotria suterella Müll. Arg. & $13226 *$ & - & - & - & - & - \\
\hline P. vellosiana Benth. & 9860 & 79 & 27 & 0,2700 & 3,67 & 10,0 \\
\hline Randia nitida (Kunth) DC. & $16920 *$ & - & - & - & - & - \\
\hline Rudgea jasminoides (Cham.) Müll. Arg. & 16296 & 40 & 13 & 0,2009 & 1,94 & 10,0 \\
\hline R. viburnoides (Cham.) Benth. & $8952 *$ & - & - & - & - & - \\
\hline \multicolumn{7}{|l|}{ RUTACEAE } \\
\hline Citrus limonia Osbeck & PD-6* & - & - & - & - & - \\
\hline Dictyoloma vandellianum A. Juss. & $13220^{*}$ & - & - & - & - & - \\
\hline Esenbeckia grandiflora Mart. & $14657 *$ & - & - & - & - & - \\
\hline Galipea jasminiflora (A. St.-Hil.) Engler & $16922 *$ & - & - & - & - & - \\
\hline Metrodorea stipularis Mart. & 16923 & 2 & 2 & 0,1482 & 0,41 & 15,0 \\
\hline Zanthoxylum caribaeum Lam. & PD-18* & - & - & - & - & - \\
\hline Z. fagara (L.) Sargent & 16596 & 1 & 1 & 0,0254 & 0,12 & 13,0 \\
\hline Z. rhoifolium Lam. & 16598 & 11 & 10 & 0,1094 & 0,94 & 12,0 \\
\hline Z. riedelianum Engler & $13005^{*}$ & - & - & - & - & - \\
\hline \multicolumn{7}{|l|}{ SABIACEAE } \\
\hline Meliosma brasiliensis Urban & 17350 & 1 & 1 & 0,0853 & 0,23 & 15,0 \\
\hline M. sellowii Urban & 16962 & 3 & 3 & 0,0401 & 0,29 & 8,0 \\
\hline \multicolumn{7}{|l|}{ SALICACEAE } \\
\hline Casearia arborea (L.C. Rich.) Urban & 12202 & 1 & 1 & 0,0033 & 0,08 & 7,0 \\
\hline C. decandra Jacquin & 9614 & 21 & 14 & 0,2249 & 1,58 & 11,0 \\
\hline C. lasiophylla Eichler & 9729 & 1 & 1 & 0,0030 & 0,08 & 8,0 \\
\hline C. obliqua Sprengel & 12839 & 41 & 27 & 0,6741 & 3,49 & 17,0 \\
\hline C. sylvestris Swartz & 9598 & 20 & 13 & 0,1368 & 1,35 & 9,0 \\
\hline Xylosma ciliatifolia (Clos) Eichler & 12837 & 3 & 3 & 0,0372 & 0,28 & 10,0 \\
\hline \multicolumn{7}{|l|}{ SAPINDACEAE } \\
\hline Allophylus semidentatus (Miq.) Radlk. & 12588 & 1 & 1 & 0,0055 & 0,08 & 5,0 \\
\hline Cupania vernalis Cambess. & 16925 & 54 & 30 & 0,3079 & 3,28 & 12,0 \\
\hline Matayba elaeagnoides Radlk. & 13330 & 27 & 15 & 0,1585 & 1,65 & 16,0 \\
\hline M. juglandifolia (Cambess.) Radlk. & 12559 & 31 & 14 & 0,5127 & 2,34 & 14,0 \\
\hline \multicolumn{7}{|l|}{ SIPARUNACEAE } \\
\hline Siparuna cujabana (Mart.) A. DC. & $1316^{*}$ & - & - & - & - & - \\
\hline S. guianensis Aublet & $3286^{*}$ & - & - & - & - & - \\
\hline \multicolumn{7}{|l|}{ SOLANACEAE } \\
\hline Brunfelsia brasiliensis (Sprengel) Smith \& Downs & 9615 & 1 & 1 & 0,0025 & 0,08 & 3,5 \\
\hline Cestrum schlechtendalii G. Don & $15467 *$ & - & - & - & - & - \\
\hline C. sendtnerianum Mart. & $16605^{*}$ & - & - & - & - & - \\
\hline Solanum bullatum Vell. & 17393* & - & - & - & - & - \\
\hline S. cernuum Vell. & $15226 *$ & - & - & - & - & - \\
\hline S. granuloso-leprosum Dunal & $13040 *$ & - & - & - & - & - \\
\hline S. leucodendron Sendt. & 12468 & 1 & 1 & 0,0097 & 0,09 & 11,0 \\
\hline S. pseudoquina A. St.-Hil. & 16608 & 4 & 4 & 0,0529 & 0,38 & 8,0 \\
\hline S. swartzianum Roem. \& Schult. & $17370 *$ & - & - & - & - & - \\
\hline \multicolumn{7}{|l|}{ STYRACACEAE } \\
\hline Styrax camporus Pohl & $7629 *$ & - & - & - & - & - \\
\hline S. ferrugineus Nees \& Mart. & 14998* & - & - & - & - & - \\
\hline S. latifolius Pohl & 16611 & 12 & 11 & 0,1726 & 1,12 & 16,0 \\
\hline \multicolumn{7}{|l|}{ SYMPLOCACEAE } \\
\hline Symplocos lanceolata (Mart.) A. DC. & 8805 & 1 & 1 & 0,0021 & 0,08 & 6,0 \\
\hline S. pubescens Klotzsch & 12836 & 1 & 1 & 0,0035 & 0,08 & 5,0 \\
\hline \multicolumn{7}{|l|}{ TERNSTROEMIACEAE } \\
\hline Gordonia fruticosa (Schrader) H. Keng. & $4449 *$ & - & - & - & - & - \\
\hline Ternstroemia brasiliensis Cambess. & 16302 & 4 & 3 & 0,0598 & 0,35 & 8,0 \\
\hline
\end{tabular}




\begin{tabular}{|c|c|c|c|c|c|c|}
\hline Famílias/Espécies & $\mathrm{Nr}$ & NI & $\mathrm{P}$ & $\mathrm{AB}\left(\mathrm{m}^{2}\right)$ & $\mathrm{VI}$ & $A(m)$ \\
\hline \multicolumn{7}{|l|}{ THYMELAEACEAE } \\
\hline Daphnopsis brasiliensis Mart. \& Zucc. & $16938^{*}$ & - & - & - & - & - \\
\hline D. fasciculata (Meisner) Nevling & 9938 & 42 & 24 & 0,4526 & 2,97 & 11,0 \\
\hline \multicolumn{7}{|l|}{ URTICACEAE } \\
\hline Cecropia glaziovii Snethl. & 16403 & 2 & 2 & 0,0179 & 0,18 & 13,0 \\
\hline C. pachystachya Trécul & 15505* & - & - & - & - & - \\
\hline Urera baccifera (L.) Gaud. & 16942 & 1 & 1 & 0,0100 & 0,09 & 5,0 \\
\hline \multicolumn{7}{|l|}{ VOCHYSIACEAE } \\
\hline Callisthene minor Mart. & 1063* & - & - & - & - & - \\
\hline Qualea cordata (Mart.) Sprengel & 16303 & 14 & 11 & 0,2914 & 1,39 & 16,0 \\
\hline Q. dichotoma (Mart.) Warm. & $15767 *$ & - & - & - & - & - \\
\hline Q. multiflora Mart. & 6177 & 3 & 2 & 0,0424 & 0,24 & 10,0 \\
\hline Vochysia magnifica Warm. & 16306 & 100 & 20 & 16,1960 & 6,30 & 18,0 \\
\hline V. thyrsoidea Pohl & 7779* & - & - & - & - & - \\
\hline V. tucanorum Mart. & 11564 & 20 & 19 & 0,3100 & 1,94 & 15,0 \\
\hline \multicolumn{7}{|l|}{ WINTERACEAE } \\
\hline Drimys brasiliensis Miers & 13044 & 1 & 1 & 0,0094 & 0,09 & 9,0 \\
\hline
\end{tabular}

Variáveis topográficas e edáficas - Foram identificadas, nas três transecções amostrais da floresta do PEQRB, quatro classes de solo (Fig. 2). A primeira classe foi constituída pelos Neossolos Litólicos Distróficos típicos, que compreendem solos com horizonte A ou O hístico com menos de $40 \mathrm{~cm}$ de espessura e assente diretamente sobre rochas ou sobre um horizonte C. Estes solos foram amostrados em 20 parcelas, distribuídas nas três transecções. A segunda classe compreendeu os Neossolos Regolíticos Distróficos típicos, que são solos incipientes com horizonte A sobrejacente ao horizonte $\mathrm{C}$, às vezes com horizonte Bi com menos de $10 \mathrm{~cm}$ de espessura e apresentando contato lítico a uma profundidade maior que $50 \mathrm{~cm}$. Estes solos foram amostrados em 10 parcelas da transecção C. A terceira e quarta classes identificadas foram a dos Cambissolos Háplicos Tb Distróficos lépticos, amostrados em 24 parcelas das transecções A e B, e os Cambissolos Háplicos Tb Distróficos típicos, amostrados em 26 parcelas da transecção C. Os Cambissolos, de maneira geral, são solos constituídos por material mineral com horizonte B incipiente (Bi) subjacente a qualquer tipo de horizonte superficial. As quatro classes de solos serão chamadas, daqui em diante, de Neossolos Litólicos, Neossolos Regolíticos, Cambissolos Lépticos e Cambissolos Típicos.

As médias e desvios padrões das variáveis topográficas e edáficas nas subamostras correspondentes às quatro classes de solo encontram-se na Tabela 2, juntamente com os resultados de comparações estatísticas. Para as variáveis topográficas, não houve diferença significativa entre os solos para a cota média, mas o desnível do terreno foi mais acentuado nos Neossolos Regolíticos, decrescendo no sentido dos Cambissolos Típicos, Neossolos Litólicos e Cambissolos Lépticos. A distância vertical até o córrego foi maior nos Cambissolos Típicos e menor nos Cambissolos Lépticos. As quatro classes de solos apresentam textura franco-arenosa e têm acentuado caráter distrófico. Não houve diferença significativa entre as quatro classes de solo para proporções de areia, silte e argila. Contudo, os Neossolos Regolíticos destacam-se pelos maiores teores de $\mathrm{P}, \mathrm{K}$, Ca e Mg, resultando em maior saturação por bases. Os Cambissolos Lépticos destacam-se pelo $\mathrm{pH}$ mais baixo e teor de $\mathrm{Al}$ mais alto e os Cambissolos Típicos, pelo teor mais baixo de matéria orgânica.

Estrutura e diversidade da comunidade arbórea - Na área total de 2,4ha foram amostrados 4.137 indivíduos, os quais somaram área basal de $20,5 \mathrm{~m}^{2} / \mathrm{ha}$. Em valores absolutos, a densidade foi maior nos Cambissolos Lépticos e a área basal, nos Cambissolos Típicos, porém não houve diferenças significativas tanto para densidade quanto para área basal entre as quatro classes de solos amostradas (Tab. 3). Por outro lado, houve contrastes significativos entre os solos nas comparações das médias de diâmetro e altura por parcela. O DAP médio foi significativamente mais alto nos Neossolos Regolíticos que nos Neossolos Litólicos e Cambissolos Lépticos; e não diferiu significativamente entre os Cambissolos Típicos. A altura média foi significativamente mais alta nos Neossolos Regolíticos que nos Cambissolos Típicos; as duas outras classes 
Tabela 2. Variáveis topográficas do terreno e variáveis químicas e texturais das amostras do solo superficial (0-20cm de profundidade) das 80 parcelas empregadas para amostrar a floresta do PEQRB, Lavras, MG. Os valores são médias \pm desvios padrão das $N$ amostras de cada uma das quatro classes de solo. Testes de $F$ indicaram diferenças significativas entre os quatro solos; as médias seguidas de letras diferentes são significativamente diferentes em testes de Tukey-Kramer.

\begin{tabular}{|c|c|c|c|c|c|c|}
\hline \multirow[t]{2}{*}{ Variáveis } & \multirow{2}{*}{$\begin{array}{c}\begin{array}{c}\text { Neossolos } \\
\text { Litólicos }\end{array} \\
N=20\end{array}$} & \multirow{2}{*}{$\begin{array}{c}\text { Cambissolos } \\
\text { Lépticos } \\
N=24\end{array}$} & \multirow{2}{*}{$\begin{array}{c}\text { Cambissolos } \\
\text { Típicos } \\
N=26\end{array}$} & \multirow{2}{*}{$\begin{array}{c}\begin{array}{c}\text { Neossolos } \\
\text { Regolíticos }\end{array} \\
N=10\end{array}$} & \multicolumn{2}{|c|}{ ANOVAs } \\
\hline & & & & & $F$ & $p$ \\
\hline Cota média $(m)$ & $86 \pm 42$ & $66 \pm 14$ & $141 \pm 22$ & $106 \pm 7$ & 0,80 & 0,497 \\
\hline Desnível (m) & $8,1 \pm 2,5$ bc & $7,1 \pm 2,4 \quad \mathrm{c}$ & $9,5 \pm 3,1 \quad a b$ & $12,0 \pm 2,6$ a & 9,24 & $<10^{-3}$ \\
\hline Distância vertical (m) & $24,6 \pm 26,2 \mathrm{~b}$ & $7,6 \pm 5,6 \quad c$ & $45,7 \pm 21,9 \mathrm{a}$ & $10,7 \pm 7,1$ bc & 19,69 & $<10^{-3}$ \\
\hline $\mathrm{pH}$ em $\mathrm{H}_{2} \mathrm{O}$ & $4,5 \pm 0,2$ a & $4,1 \pm 0,2 b$ & $4,5 \pm 0,2 \quad a$ & $4,6 \pm 0,2 \quad a$ & 21,28 & $<10^{-3}$ \\
\hline $\mathrm{P}-$ Mehlich $\left(\mathrm{mg} / \mathrm{dm}^{3}\right)$ & $3,4 \pm 0,9 \quad b$ & $3,5 \pm 0,9 b$ & $3,6 \pm 0,6 b$ & $6,6 \pm 3,1 \quad a$ & 15,93 & $<10^{-3}$ \\
\hline $\mathrm{K}+\left(\mathrm{mg} / \mathrm{dm}^{3}\right)$ & $47 \pm 15 \quad b$ & $48 \pm 17 \quad b$ & $39 \pm 7 \quad b$ & $65 \pm 19$ a & 8,16 & $<10^{-3}$ \\
\hline $\mathrm{Ca}++\left(\mathrm{cmolc} / \mathrm{dm}^{3}\right)$ & $0,3 \pm 0,1 \quad b$ & $0,2 \pm 0,1 \quad b$ & $0,3 \pm 0,1 \quad b$ & $0,8 \pm 0,4 \quad$ a & 24,84 & $<10^{-3}$ \\
\hline $\mathrm{Mg}++\left(\mathrm{cmolc} / \mathrm{dm}^{3}\right)$ & $0,11 \pm 0,03 \mathrm{~b}$ & $0,11 \pm 0,03 b$ & $0,13 \pm 0,04 b$ & $0,26 \pm 0,23 \mathrm{a}$ & 7,86 & $<10^{-2}$ \\
\hline $\mathrm{Al}+++\left(\mathrm{cmolc} / \mathrm{dm}^{3}\right)$ & $2,6 \pm 0,5 \quad b$ & $3,3 \pm 0,7 \quad a$ & $2,5 \pm 0,5 b$ & $2,6 \pm 0,8 \quad b$ & 24,84 & $<10^{-3}$ \\
\hline V, saturação por bases (\%) & $3,1 \pm 1,1 \quad \mathrm{c}$ & $2,5 \pm 0,9 \quad c$ & $4,3 \pm 1,0 \quad b$ & $7,4 \pm 2,9$ a & 33,60 & $<10^{-3}$ \\
\hline Matéria orgânica (dag/kg) & $7,0 \pm 2,4 \quad$ a & $6,2 \pm 1,8 a b$ & $4,0 \pm 0,8 \quad c$ & $5,2 \pm 1,2$ b & 33,60 & $<10^{-3}$ \\
\hline Areia (\%) & $48,6 \pm 12,5$ & $50,4 \pm 11,0$ & $51,0 \pm 5,1$ & $50,9 \pm 11,2$ & 0,24 & 0,866 \\
\hline Silte (\%) & $32,4 \pm 7,6$ & $29,1 \pm 5,9$ & $27,2 \pm 3,8$ & $29,7 \pm 10,8$ & 2,41 & 0,072 \\
\hline Argila (\%) & $19,0 \pm 7,1$ & $20,5 \pm 6,4$ & $21,8 \pm 2,6$ & $19,4 \pm 11,5$ & 0,80 & 0,497 \\
\hline
\end{tabular}

${ }^{1}$ Para altitude, acrescentar $1.000 \mathrm{~m}$.

não diferiram significativamente. Estas diferenças ficam mais evidentes quando se comparam as distribuições da densidade de árvores por classes de diâmetro e altura (Fig. 3). A densidade de árvores na classe de 5 a 9cm diâm. foi maior no Cambissolo Léptico e menor para o Neossolo Regolítico. Para as demais classes não houve diferenças marcantes. Para as classes de altura, destacam-se os dois Cambissolos com maior densidade na classe de 5 a 10m. Nas demais classes, as diferenças são insignificantes.

Os 4.137 espécimes amostrados nas parcelas distribuíram-se em 213 espécies e 58 famílias botânicas. Este número de espécies representa 75 a $82 \%$ da riqueza total esperada pelos estimadores jackknife de primeira e segunda ordem, respectivamente (Tab. 3). No levantamento florístico, que incluiu coletas feitas

Tabela 3. Variáveis da estutura fisionômica e variáveis relacionadas à diversidade de espécies nas parcelas utilizadas para amostrar a comunidade arbórea da floresta do PEQRB, Lavras, MG, distribuídas nas quatro classes de solo. Valores com amplitudes são médias \pm desvios padrão; onde testes de $F$ indicaram diferenças significativas entre as quatro classe de solo, médias seguidas da mesma letra não diferiram significativamente em testes de Tukey-Kramer. Índices de Shannon seguidos da mesma letra não diferiram significativamente entre si em testes de $t$ de Hutcheson.

\begin{tabular}{|c|c|c|c|c|c|c|}
\hline Variáveis & Total & $\begin{array}{l}\text { Neossolos } \\
\text { Litólicos }\end{array}$ & $\begin{array}{c}\text { Cambissolos } \\
\text { Lépticos }\end{array}$ & $\begin{array}{c}\text { Cambissolos } \\
\text { Típicos }\end{array}$ & $\begin{array}{l}\text { Neossolos } \\
\text { Regolíticos }\end{array}$ & ANOVAs \\
\hline Número de parcelas de $300 \mathrm{~m}^{2}$ & 80 & 20 & 24 & 26 & 10 & \\
\hline Número de indivíduos & 4137 & 986 & 1367 & 1357 & 427 & \\
\hline Densidade (ind.ha ${ }^{-1}$ ) & $1643 \pm 736$ & $1643 \pm 736$ & $1899 \pm 755$ & $1740 \pm 254$ & $1423 \pm 229$ & $F=1,76 p=0,161$ \\
\hline Área basal $\left(\mathrm{m}^{2} \cdot \mathrm{ha}^{-1}\right)$ & $20,5 \pm 8,9$ & $20,5 \pm 8,9$ & $22,4 \pm 8,6$ & $26,0 \pm 7,4$ & $21,0 \pm 2,8$ & $F=2,22 p=0,093$ \\
\hline DAP médio $(\mathrm{cm})$ & $10,8 \pm 1,4$ & $10,8 \pm 1,4^{b}$ & $10,7 \pm 1,3^{b}$ & $11,6 \pm 1,1^{\mathrm{ab}}$ & $12,0 \pm 1,0^{\mathrm{a}}$ & $F=4,53 p=0,0056$ \\
\hline Altura média (cm) & $8,1 \pm 1,4$ & $8,1 \pm 1,4^{\mathrm{ab}}$ & $8,5 \pm 1,1^{\mathrm{ab}}$ & $7,9 \pm 0,6^{\mathrm{b}}$ & $8,9 \pm 0,8^{\mathrm{a}}$ & $F=2,74 p=0,049$ \\
\hline Número de espécies & 213 & 121 & 136 & 142 & 97 & \\
\hline Densidade de espécies & $26,5 \pm 6,1$ & $23,7 \pm 7,3^{b}$ & $26,1 \pm 5,3^{\mathrm{ab}}$ & $29,6 \pm 5,1^{\text {a }}$ & $25,1 \pm 4,6^{\mathrm{ab}}$ & $F=4,38 p=0,0067$ \\
\hline Índice de Shannon, $H^{\prime}$ (nats.ind..$^{-1}$ ) & 4,56 & $4,04^{\mathrm{b}}$ & $4,08^{\mathrm{b}}$ & $4,27^{\mathrm{a}}$ & $4,03^{\mathrm{b}}$ & \\
\hline Equabilidade de Pielou, $J$ & 0,85 & 0,84 & 0,83 & 0,86 & 0,88 & \\
\hline Estimador jackknife; $1^{\text {a }}$ ordem & 259,4 & 158,1 & 175,3 & 180,5 & 124,5 & \\
\hline Estimador jackknife; $2^{\mathrm{a}}$ ordem & 283,1 & 174,4 & 192,7 & 207,6 & 138,3 & \\
\hline
\end{tabular}


A

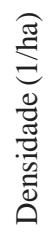

Classes de DAP (cm)

Classes de altura (m)

Figura 3. Distribuição da densidade de árvores com DAP $\geq 5 \mathrm{~cm}$ em classes de diâmetro (A) e altura (B) nas parcelas utilizadas para amostrar a comunidade arbórea da floresta do PEQRB, Lavras, MG, distribuídas nas quatro classes de solo. As barras são médias aritméticas e as linhas são médias mais desvios padrão. $\square=$ Neossolos Litólicos; $\boxminus$ = Cambissolos Lépticos; $\square$ = Cambissolos Típicos; $\square$ = Neossolos Regolíticos.

fora das parcelas, o número de espécies foi de 384, superando em mais de 100 espécies o número esperado pelo estimador jackknife de segunda ordem. O índice de diversidade de Shannon ( $H^{\prime}$ ) foi de 4,56 nats.ind. ${ }^{-1}$ e o índice de eqüabilidade de Pielou ( $J^{\prime}$ ), de 0,85 para a amostra total. $\mathrm{O}$ valor de $\mathrm{H}^{\prime}$ foi significativamente maior nos Cambissolos Típicos que nas demais classes de solo. Como a eqüabilidade de Pielou teve valores próximos em todas as classes de solo, o maior índice de Shannon dos Cambissolos Típicos deve-se certamente à maior riqueza de espécies. A densidade de espécies por parcela também foi significativamente mais elevada nos Cambissolos Típicos do que nos Neossolos Litólicos, mas não houve diferença significativa entre estes extremos e as duas outras classes de solo.

A Tabela 1 apresenta os parâmetros fitossociológicos das espécies amostradas nas 80 parcelas. As dez espécies que apresentaram os maiores valores de
VI (valor de importância) foram: Tapirira obtusa, Sclerolobium rugosum, Siphoneugena densiflora, Copaifera langsdorffii, Pera glabrata, Miconia trianae, Alchornea triplinervia, Vochysia magnifica, Croton verrucosus e Amaioua guianensis. Juntas, estas espécies representaram 26,91\% do VI total. As 10 espécies que apresentaram maior densidade foram: T. obtusa, S. densiflora, C. langsdorffii, Amaioua guianensis, M. trianae, V. magnifica, Protium widgrenii, P. glabrata, Gymnanthes concolor e Psychotria vellosiana. Estas espécies, juntas, representaram 29,82\% dos indivíduos registrados. As cinco espécies que apresentaram maior área basal foram S. rugosum, T. obtusa, C. langsdorffii, $P$. glabrata e $S$. densiflora que, juntas, representaram 23,06\% da área basal total.

Na Tabela 4 são apresentados os valores dos parâmetros fitossociológicos das 10 espécies de maior VI para as quatro classes de solo amostradas. Algumas espécies são compartilhadas nestas posições entre as classes de solo. T. obtusa e $S$. densiflora são as únicas compartilhadas pelos quatro solos. S. rugosum e C. langsdorffii ocorrem nos Neossolos Litólicos e Cambissolos Lépticos, $M$. trianae e C. verrucosus ocorrem nos Neossolos Litólicos e Cambissolos Típicos, Coccoloba warmingii ocorre nos Neossolos Regolíticos e Cambissolos Lépticos, A. triplinervia ocorre nos Cambissolos Lépticos e Típicos e Croton floribundus e V. magnifica ocorrem nos Cambissolos Típicos e Neossolos Regolíticos. As outras 16 espécies ocorrem em só uma classe de solo.

Padrões de distribuição das espécies - Os autovalores da análise de correspondência canônica (CCA) foram baixos, 0,362 (eixo 1) e 0,224 (eixo 2), confirmando a existência de gradientes 'curtos' sensu ter Braak (1995), nos quais há mais variação nas abundâncias relativas das espécies do que na substituição de espécies. Os dois primeiros eixos da CCA explicaram em conjunto apenas 16,5\% (eixo 1, 10,2\% e eixo 2, 6,3\%) da variância global dos dados, indicando que grande proporção da variância permaneceu sem explicação. Os baixos valores observados de variância percentual para abundância de espécies são comuns em dados de vegetação e não prejudicam a significância das relações espécie-ambiente (ter Braak 1988). De fato, a CCA produziu valores muito altos para as correlações espécie-ambiente nos eixos 1 e 2: 0,923 e 0,821, respectivamente. Além disso, os testes de permutação de Monte Carlo indicaram, para os dois eixos de ordenação, que os gradientes das 
Tabela 4. Espécies da comunidade arbórea da floresta do PEQRB, Lavras, MG, com os dez maiores valores de importância (VI) em cada uma das quatro classes de solo, seguidas de seus parâmetros quantitativos: $\mathrm{NI}$ = número de indivíduos; Parc = número de parcelas com ocorrência da espécie; $\mathrm{AB}$ = área basal; Amx = altura máxima; Amd = altura média. Classes de solo e número de parcelas de 10×30m: NL (Neossolos Litólicos), $N$ = 20; CL (Cambissolos Lépticos), $N=$ 24; CT (Cambissolos Típicos), $N$ = 26; NR (Neossolos Regolíticos), $N=10$.

\begin{tabular}{|c|c|c|c|c|c|c|c|}
\hline Solo & Espécie & NI & Parc & $\mathrm{AB}\left(\mathrm{m}^{2}\right)$ & VI & $\operatorname{Amx}(\mathrm{m})$ & Amd (m) \\
\hline NL & Eremanthus erythropappus & 70 & 12 & 1,2850 & 20,08 & 19,0 & 7,9 \\
\hline NL & Sclerolobium rugosum & 28 & 17 & 1,4200 & 17,97 & 22,0 & 9,9 \\
\hline NL & Tapirira obtusa & 59 & 18 & 0,8313 & 16,54 & 20,0 & 8,1 \\
\hline NL & Psychotria vellosiana & 67 & 17 & 0,2371 & 12,31 & 10,0 & 5,8 \\
\hline NL & Siphoneugena densiflora & 39 & 10 & 0,6296 & 11,18 & 15,0 & 8,3 \\
\hline NL & Miconia chartacea & 48 & 16 & 0,3382 & 10,99 & 15,0 & 8,5 \\
\hline NL & Copaifera langsdorffii & 46 & 10 & 0,4266 & 10,24 & 12,0 & 8,3 \\
\hline NL & Myrsine umbellata & 36 & 15 & 0,2329 & 8,71 & 13,0 & 7,7 \\
\hline NL & Miconia trianae & 23 & 11 & 0,4330 & 8,17 & 20,0 & 9,2 \\
\hline NL & Croton verrucosus & 22 & 11 & 0,3877 & 7,70 & 22,0 & 11,7 \\
\hline CL & Sclerolobium rugosum & 22 & 10 & 2,3040 & 17,47 & 25,0 & 17,3 \\
\hline CL & Peraglabrata & 68 & 18 & 1,3942 & 16,48 & 19,0 & 10,1 \\
\hline CL & Amaioua guianensis & 123 & 17 & 0,7143 & 16,13 & 13,0 & 7,5 \\
\hline CL & Copaifera langsdorffii & 88 & 13 & 1,1555 & 15,67 & 16,0 & 8,7 \\
\hline CL & Tapirira obtusa & 50 & 21 & 0,9496 & 12,89 & 18,0 & 9,4 \\
\hline CL & Protium widgrenii & 70 & 19 & 0,5806 & 11,75 & 14,0 & 7,9 \\
\hline CL & Siphoneugena densiflora & 85 & 18 & 0,3971 & 11,55 & 14,0 & 7,8 \\
\hline CL & Coccoloba warmingii & 33 & 13 & 0,4449 & 7,24 & 15,0 & 9,1 \\
\hline CL & Alchornea triplinervia & 18 & 11 & 0,5560 & 6,52 & 18,0 & 12,6 \\
\hline CL & Faramea cyanea & 36 & 13 & 0,2813 & 6,45 & 10,0 & 6,5 \\
\hline $\mathrm{CT}$ & Vochysia magnifica & 82 & 17 & 1,2693 & 14,51 & 18,0 & 9,1 \\
\hline $\mathrm{CT}$ & Miconia trianae & 101 & 21 & 0,5543 & 12,90 & 12,0 & 7,3 \\
\hline $\mathrm{CT}$ & Tapirira obtusa & 68 & 22 & 0,9317 & 12,46 & 12,0 & 7,9 \\
\hline $\mathrm{CT}$ & Myrcia fallax & 61 & 20 & 0,3490 & 8,81 & 12,0 & 6,6 \\
\hline $\mathrm{CT}$ & Alchornea triplinervia & 36 & 18 & 0,7581 & 8,73 & 14,0 & 9,4 \\
\hline $\mathrm{CT}$ & Prunus myrtifolia & 40 & 19 & 0,6442 & 8,59 & 14,0 & 7,6 \\
\hline $\mathrm{CT}$ & Siphoneugena densiflora & 37 & 15 & 0,5133 & 7,21 & 15,0 & 7,6 \\
\hline $\mathrm{CT}$ & Croton verrucosus & 22 & 11 & 0,7179 & 6,59 & 18,0 & 11,4 \\
\hline $\mathrm{CT}$ & Croton floribundus & 24 & 15 & 0,3994 & 5,69 & 13,0 & 8,0 \\
\hline $\mathrm{CT}$ & Myrcia rostrata & 26 & 16 & 0,3165 & 5,55 & 14,0 & 7,1 \\
\hline NR & Coccoloba warmingii & 15 & 6 & 0,4926 & 13,72 & 16,0 & 10,6 \\
\hline NR & Calycorectes acutatus & 25 & 7 & 0,2726 & 12,97 & 11,0 & 8,7 \\
\hline NR & Rudgea jasminoides & 31 & 7 & 0,1632 & 12,64 & 10,0 & 7,2 \\
\hline NR & Gymnanthes concolor & 24 & 9 & 0,1531 & 11,63 & 10,0 & 7,1 \\
\hline NR & Matayba juglandifolia & 19 & 7 & 0,2487 & 11,18 & 14,0 & 8,6 \\
\hline NR & Vochysia magnifica & 18 & 3 & 0,3503 & 10,97 & 18,0 & 9,7 \\
\hline NR & Tapirira obtusa & 13 & 7 & 0,2781 & 10,25 & 17,0 & 8,7 \\
\hline NR & Croton floribundus & 9 & 7 & 0,2004 & 8,08 & 15,0 & 9,1 \\
\hline NR & Aspidosperma parvifolium & 8 & 6 & 0,2292 & 7,90 & 18,0 & 11,1 \\
\hline NR & Siphoneugena densiflora & 10 & 6 & 0,1813 & 7,61 & 18,0 & 10,9 \\
\hline
\end{tabular}

abundâncias das espécies diferem significativamente de padrões aleatórios ( $P<0,01$ para autovalores) e que as abundâncias das espécies foram significativamente correlacionadas com as variáveis ambientais utilizadas $(P<0,01$ para correlações espécies-variáveis). As correlações das variáveis ambientais com o primeiro eixo de ordenação foram, em ordem decrescente de valor absoluto, para fator borda (0,927), $\mathrm{Al}(0,675)$, cota $(-0,636), \mathrm{pH}(-0,560)$, saturação por bases $(-0,549)$ e matéria orgânica $(0,530)$ e classes de drenagem $(-0,312)$. A variável classes de drenagem apresentou correlação mais forte com o segundo eixo de ordenação $(0,850)$, as demais foram todas inferiores a 0,500.

No diagrama de ordenação das parcelas (Fig. 4A), pode-se observar que as quatro classes de solo foram discriminadas em setores diferentes do diagrama, o que reforça a visão das mesmas como hábitats bem 
definidos e com composição de espécies particular porque as classes de solos em si não interferem no resultado da CCA. O primeiro eixo da CCA discriminou, à esquerda, parcelas de Neossolos Regolíticos e Cambissolos Típicos como apresentando cotas mais
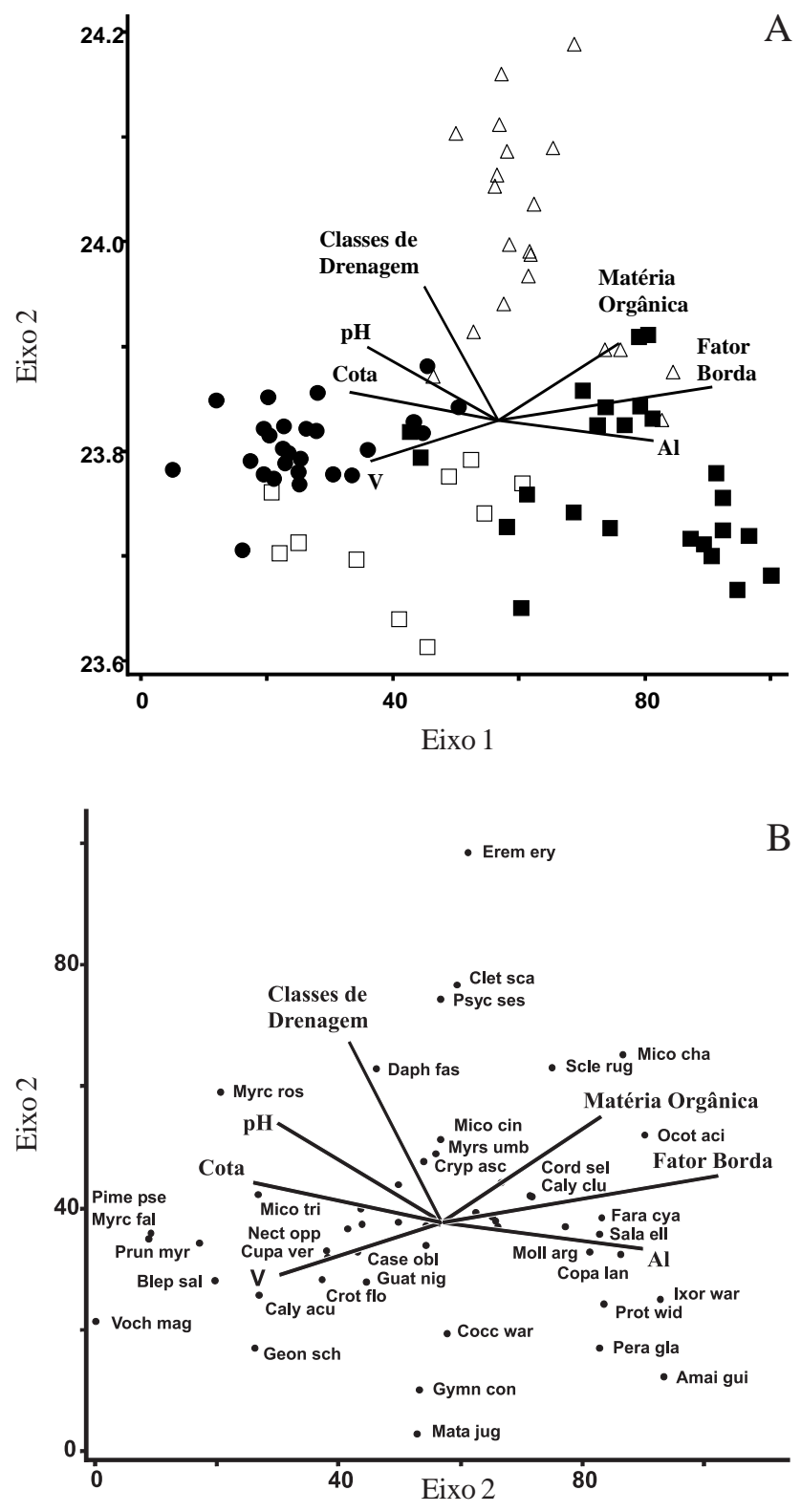

Figura 4. Análise de correspondência canônica (CCA): diagramas de ordenação das parcelas (A) e espécies (B) baseados na distribuição do número de indivíduos de 50 espécies em 80 parcelas da floresta do PEQRB, Lavras, MG, e sua correlação com as sete variáveis ambientais utilizadas (retas). As classes de solo das parcelas são indicadas por símbolos diferentes. As espécies são indicadas pelos seus nomes abreviados (vide Tabela 4). Os nomes de 13 espécies aglomeradas no centro do diagrama foram omitidos. $\mathrm{V}$ = saturação por bases, $\mathrm{Al}=$ teor de alumínio, $\triangle=$ Neossolos Litólicos, $\boldsymbol{\square}=$ Cambissolos Lépticos, - = Cambissolos Típicos, $\square=$ Neossolos Regolíticos. elevadas (transecção C), pH e V mais altos, teores de alumínio mais baixos e efeito borda menos pronunciado. As tendências inversas se apresentam no lado direito do diagrama, onde se concentram parcelas de Cambissolos Lépticos (Transecções A e B). O segundo eixo da CCA discriminou, na parte superior, as parcelas dos Neossolos Litólicos, associadas a uma drenagem mais forte. O diagrama de ordenação das espécies (Fig. 4B) sugere que Myrcia rostrata, Daphnopsis fasciculata, Psychotria vellosiana, Clethra scabra e Eremanthus erythropappus tendem a ser mais abundantes nas áreas com drenagem mais acentuada, distantes da margem do córrego, próximas à borda da floresta e com predominância do Neossolos Litólicos. Por outro lado, espécies como Faramea cyanea, Ixora warmingii, Salacia elliptica e Copaifera langsdorffii são mais abundantes junto à borda da floresta ou nos solos com maior teor de alumínio e menor V. Outras espécies, como Pimenta pseudocaryophyllus, Myrcia fallax e Prunus myrtifolia, tendem a ser mais abundantes quanto mais distantes estiverem da borda e/ou em solos de maior V e menor teor de alumínio.

\section{Discussão}

Composição florística e diversidade de espécies - Devido principalmente à sua grande heterogeneidade ambiental, as matas ripárias apresentam, em geral, riqueza de espécies elevada em relação às florestas vizinhas não associadas a cursos d’água (Oliveira-Filho et al. 1990; Durigan et al. 2000). A alta riqueza de espécies encontrada na floresta do PEQRB deve-se, provavelmente, à combinação de vários fatores. Salienta-se a forte heterogeneidade ambiental incrementada pela condição ripária de parte da floresta, pelo pronunciado gradiente edáfico e topográfico e pelo efeito borda na sua transição para as formações campestres. Deve-se considerar que o PEQRB representa uma área de transição entre florestas, cerrados e campos onde o contato entre formações fisionômicas distintas pode contribuir para o enriquecimento da flora, conforme já observado por Botrel et al. (2002) no vizinho município de Ingaí. A grande heterogeneidade da vegetação e ambiente certamente não foi bem representada pelas transecções amostrais, o que foi confirmado pelos estimadores 'jackknife' projetados a partir das mesmas, pois estes foram largamente superados pelo número de espécies registrado no levantamento florístico total.

Apesar das considerações acima, a alta riqueza de espécies da floresta do PEQRB não pode ser 
atribuída primariamente à intensa amostragem, pois esta registrou o maior valor de riqueza de espécies entre 20 áreas de floresta da região do Alto Rio Grande de cujos inventários Pereira (2003) extraiu subamostras médias de igual tamanho. De acordo com este autor, a alta heterogeneidade ambiental do PEQRB é a razão principal de sua alta riqueza de espécies em relação às outras 19 florestas. A esta heterogeneidade ambiental soma-se a transição com as formações abertas, que incrementa a riqueza de espécies. Para se ter uma idéia da riqueza de espécies na floresta do PEQRB, pode-se também comparar seu total de 384 espécies arbóreas com as 730 encontradas nas mesmas 20 florestas da região, o que significa representação de 52,6\% da lista total da região contida em área relativamente pequena. O índice de diversidade de Shannon para as florestas do PEQRB $\left(H^{\prime}=4,56\right.$ nats.ind. $\left.{ }^{-1}\right)$ também é o maior valor encontrado na região do Alto Rio Grande e significativamente diferente dos demais 19 valores, de acordo com Pereira (2003). O índice de equabilidade de Pielou $\left(J^{\prime}=0,85\right)$ não se destaca da mesma maneira, mas está situado na faixa dos dez maiores valores registrados para região. Como o índice de Shannon é influenciado tanto pela riqueza de espécies quanto pela equabilidade, o alto $H^{\prime}$ deve-se mais ao componente riqueza. Da mesma forma, a heterogeneidade ambiental relativamente mais alta é provavelmente a principal responsável pelo alto índice.

Observando os valores do índice de Shannon para as quatro classes de solo, verificam-se valores altos para todas elas $\left(H^{\prime}>4,0\right.$ nats.ind. $\left.{ }^{-1}\right)$, mas os Cambissolos Típicos destacam-se pelo valor particularmente maior. Este fato provavelmente vincula-se à amostragem deste hábitat de solo, que se estendeu por faixa relativamente mais extensa que os demais. Esta faixa compreendeu desde ambiente mais úmido, próximo ao córrego (ca. 1.090m de altitude), até mais seco, na alta encosta (ca. 1.200m de altitude), o que não ocorreu para as outras classes de solo. Este fato provavelmente ocasiona heterogeneidade ambiental mais pronunciada nos Cambissolos Típicos. A densidade de espécies por parcela, significativamente mais baixa nos Neossolos Litólicos, provavelmente se explica pela predominância neste hábitat de solo da fisionomia do candeal, onde a dominância da candeia (Eremanthus erythropappus) contribui para reduzir a riqueza local de espécies.

Análise do perfil da flora arbórea da floresta do PEQRB nos níveis de famílias, gêneros e espécies mostra claras características das florestas altomontanas do Domínio da Floresta Atlântica no Sudeste do Brasil, conforme os critérios de Oliveira-Filho \& Fontes (2000). Destaca-se o grande número de espécies das famílias Myrtaceae, Melastomataceae, Lauraceae, Asteraceae, Cyatheaceae e Solanaceae e dos gêneros Miconia, Ilex, Cyathea, Clusia e Roupala. Entre as espécies típicas relacionam-se Araucaria angustifolia, Podocarpus sellowii, Drymis brasiliensis, Jacaranda subalpina, Eremanthus erythropappus, Eupatorium velutinum, Clethra scabra, Ilex sapotifolia, Euplassa organensis, Meliosma sellowii, Meliosma brasiliensis, Gordonia fruticosa e Ternstroemia brasiliensis. O pinheiro-brasileiro, A. angustifolia, é encontrado em uma área de floresta secundária adjacente ao Parque, tratando-se, provavelmente, da última população nativa remanescente da região e um extremo setentrional de distribuição geográfica natural da espécie. Outro aspecto notável é a redução da contribuição de Fabaceae para a flora das florestas neotropicais à medida que a altitude aumenta (Gentry 1995). Apesar de sua situação altitudinal próxima ao limite inferior das florestas alto-montanas $(1.100 \mathrm{~m})$ sensu Oliveira-Filho \& Fontes (2000), a proporção de espécies de Fabaceae no PEQRB (9,9\%) é inferior à de florestas baixo-montanas da região (12-16\%) (Pereira 2003).

Estrutura da comunidade arbórea - Os valores computados por Pereira (2003) para densidade e área basal por hectare das 20 áreas de floresta levantadas na região do Alto Rio Grande variam, respectivamente, entre 969 e 2.683 ind.ha $^{-1}$ e 19,8 e 43,4m²ha ${ }^{-1}$. Portanto, a floresta do PEQRB, que registrou 1.643 ind.ha $^{-1} \mathrm{e}$ $20,5 \mathrm{~m}^{2} \mathrm{ha} \mathrm{H}^{-1}$ tem densidade intermediária (10 ${ }^{\mathrm{a}}$ posição no ranking decrescente) e área basal baixa (18 posição no ranking decrescente). Do ponto de vista ambiental, a floresta do PEQRB destaca-se no contexto das demais pelo caráter fortemente distrófico dos solos associado a textura comparativamente mais grossa, assim como longo histórico de impacto pelo fogo (Pereira 2003). Portanto, é possível que maior escassez de recursos hídricos e minerais, principalmente nas áreas mais distantes do curso d'água, contribua para biomassa relativamente mais baixa, expressa pela área basal. Os impactos do fogo também podem contribuir para reduzir a área basal. Contudo, são necessários estudos de produtividade líquida e dinâmica da comunidade arbórea para confirmar esta hipótese. Indicação que pode fortalecer esta hipótese vem das menores dimensões das árvores nos Neossolos Litólicos e Cambissolos Lépticos, que também apresentam drenagem mais forte, fertilidade mais baixa e menor 
proteção contra o fogo. Também observou-se concentração de árvores mais altas e de maior diâmetro mais próximo ao córrego.

Padrões de distribuição das espécies - A análise de correspondência canônica ordenou as parcelas de acordo com as correlações entre as abundâncias das espécies e as variáveis ambientais, resultando em clara separação das quatro classes de solo identificadas previamente. Esse fato confirma a consistência da classificação dos solos e do uso das quatro classes como definidoras de hábitats. Os Neossolos Litólicos associam-se positivamente às variáveis classes de drenagem e fator borda devido à sua concentração na borda da floresta, onde a declividade é acentuada e o solo mais raso, favorecendo forte drenagem. Os Cambissolos Lépticos mostraram-se semelhantes em relação à variável borda, mas diferem quanto à drenagem, pois estão situados mais próximos ao córrego. Os Cambissolos Típicos associaram-se mais fortemente às cotas mais elevadas e de forma negativa com a borda, porque altitude é mais elevada na maioria de suas parcelas que estão também inseridas no interior da floresta, formando ambiente com menos intensidade de luz. Nos Neossolos Regolíticos, a agregação foi mais evidente no lado oposto da variável drenagem provavelmente porque em metade de suas parcelas ocorre a passagem do córrego, tornando o ambiente mais úmido e mal drenado.

O fator borda foi a variável de maior correlação na distribuição das abundâncias das espécies. As bordas são, por definição, áreas de transição entre unidades de paisagem, tendo características que dependem das escalas espacial e temporal e das forças de interação que agem sobre esta unidade (Holland 1988). São áreas de hábitat mais expostas a perturbações externas e possuem, em geral, maior diversidade, densidade de espécie e produtividade biológica (Murcia 1985; Fortin 1994). As bordas de florestas influenciam na penetração de raios solares, modificando a qualidade e quantidade de luz, a temperatura, a evapotranspiração, a incidência de ventos e a redução da umidade do ar e do solo (Murcia 1995; Kapos et al. 1997). O fragmento florestal do PEQRB, apesar de ser o maior em área do município de Lavras, apresenta forma bastante alongada, aumentando seu perímetro e a ação do efeito borda, o que pode ainda incrementar sua diversidade de espécies. Segundo van den Berg \& Oliveira-Filho (1999), nas florestas ripárias que têm bordas naturais com formações abertas, a heterogeneidade ambiental é maior na faixa ecotonal da borda, estando relacionada basicamente com a umidade do solo e a luminosidade.
A variável drenagem também demonstrou forte influência na distribuição da abundância das espécies, o que pode interferir na disponibilidade de água e na fertilidade química dos solos. Nas florestas ripárias, geralmente a umidade e a fertilidade diminuem com o aumento da cota, principalmente quando a declividade é maior, conforme já detectado por alguns trabalhos feitos na região (van den Berg \& Oliveira-Filho 1999; Botrel et al. 2002; Espírito-Santo et al. 2002; Souza et al. 2003).

A alta diversidade da comunidade arbórea da floresta do PEQRB provavelmente se deve à alta heterogeneidade ambiental incrementada pelo relevo acidentado e pelo pronunciado efeito borda nas faixas de transição entre floresta e ambientes abertos. Esta transição condiciona a existência do candeal, que representa verdadeiro ecótono entre a floresta semidecídua e os campos de altitude e rupestre. Estes fatos salientam a importância ecológica do Parque como valiosa amostra da vegetação primitiva da região do Alto Rio Grande, a qual merece atenção especial quanto à sua preservação.

\section{Referências bibliográficas}

Angiosperm Phylogeny Group II. 2003. An update of the Angiosperm phylogeny group classification for the orders and families of flowering plants: APG II Annals of the Botanical Journal of the Linnean Society 141(4): 399-436.

Botrel, R.T.; Oliveira-Filho, A.T.; Rodrigues, L.A. \& Curi, N. 2002. Influência do solo e topografia sobre as variações da composição florística e estrutura da comunidade arbóreo-arbustiva de uma floresta estacional semidecidual em Ingaí, MG. Revista Brasileira de Botânica 25(2): 195-213.

Causton, D.R. 1988. An introduction to vegetation analysis, principles and interpretation. London, Unwin Hyman.

Curi, N.; Lima, J.M.; Andrade, H. \& Gualberto, V. 1990. Geomorfologia, física, química e mineralogia dos principais solos da região de Lavras (MG). Ciência e Prática 14(2): 297-307.

Durigan, G.; Rodrigues, R.R. \& Schiavini, I. 2000. A heterogeneidade ambiental definindo a metodologia de amostragem da floresta ciliar. Pp. 159-167. In: R.R. Rodrigues \& H.F. Leitão-Filho (eds.). Matas ciliares: conservação e recuperação. São Paulo, EDUSP.

Eiten, G. 1982. Brazilian “Savannas”. Pp. 25-47. In: B.J. Huntley \& B.H. Walker (eds.). Ecology of tropical savannas. Berlim, Springer-Verlag.

EMBRAPA 1997. Manual de métodos de análise de solo. Rio de Janeiro, Empresa Brasileira de Pesquisa Agropecuária, Centro Nacional de Pesquisa de Solos.

EMBRAPA 1999. Sistema brasileiro de classificação de solos. Rio de Janeiro, Empresa Brasileira de Pesquisa Agropecuária, Centro Nacional de Pesquisa de Solos. 
Espírito-Santo, F.D.B.; Oliveira-Filho, A.T.; Machado, E.L.M.; Souza, J.S.; Fontes, M.A.L. \& Marques, J.J.G.S.M. 2002. Variáveis ambientais e a distribuição de espécies arbóreas em um remanescente de Floresta Estacional Semidecídua Montana no campus da Universidade Federal de Lavras, MG. Acta Botanica Brasilica 16(3): 331-356.

Fortin, M.J. 1994. Edge detection algorithms for twodimensional ecological data. Ecology 75(4): 956-965.

Gentry, A.H. 1995. Patterns of diversity and floristic composition in neotropical montane forests. Pp. 103-126. In: S.P. Churchill; H. Balslev; E. Forero \& J.L. Luteyn (eds.). Biodiversity and conservation of Neotropical Montane Forests: Proceedings of Neotropical Montane Forest Biodiversity and Conservation Symposium. New York, The New York Botanical Garden.

Golfari, L. 1975. Zoneamento ecológico do estado de Minas Gerais para reflorestamento. Belo Horizonte, PNUD/FAO/IBDF.

Heltsche, J.F. \& Forrester, N.E. 1983. Estimating species richness using the jackknife procedure. Biometrics 39(1): 1-12.

Holland, M.M. 1988. SCOPE/MAB technical consultations on landscape boundaries; report of a SCOPE/MAB workshop on ecotones. Pp. 47-106. In: A.F. di Castri; A.J. Hansen \& M.M. Holland (eds.). A new look at ecotones: emerging international projects on landscape boundaries. Paris, Biology International.

Kapos, V.; Camargos, J.L.C.; Dande, G. 1997. Edge related changes in environment and plant response due to forest fragmentation in Central Amazonia. Pp. 45-54. In: W.F. Laurance \& R.O. Bierregaard (eds.). Tropical forest remnats: ecology, management and conservation of fragmented communities. Chicago, The University of Chicago Press.

Krebs, C.J. 1989. Ecological methodology. New York, Harper and Row.

McCune, B. \& Mefford, M.J. 1999. Multivariate analysis of ecological data. Gleneden Beach, MjM Software.

Mueller-Dombois, D. \& Ellenberg, H. 1974. Aims and methods of vegetation ecology. New York, Wiley and Sons.

Murcia, C. 1995. Edges effects in fragmented forest: Implications for conservation. Trends in Ecology and Evolution 10(2): 58-62.

Oliveira-Filho, A.T.; Ratter, J.A. \& Shepherd, G.J. 1990. Floristic composition and community structure of a central Brazilian gallery forest. Flora 184(2): 103-117.

Oliveira-Filho, A.T.; Almeida, R.J.; Mello, J.M. \& Gavilanes, M.L. 1994a. Estrutura fitossociológica e variáveis ambientais em um trecho da mata ciliar do córrego dos Vilas Boas, Reserva Biológica do Poço Bonito, Lavras, MG. Revista Brasileira de Botânica 17(1): 67-85.

Oliveira-Filho, A.T.; Vilela, E.A.; Gavilanes, M.L. \& Carvalho, D.A. 1994b. Comparison of the woody flora and soils of six areas of montane semideciduous forest in southern Minas Gerais, Brazil. Edinburgh Journal of Botany 51(3): 355-389.
Oliveira-Filho, A.T.; Mello, J.M. \& Scolforo, J.R.S. 1997. Effects of past disturbance and edges on tree community structure and dynamics within a fragment of tropical semideciduous forest in southeastern Brazil over a five year period (1987-1992). Plant Ecology 131(1): 45-66.

Oliveira-Filho, A.T. \& Fluminhan-Filho, M. 2000. Ecologia da vegetação do Parque Florestal Quedas do Rio Bonito. Cerne 5(2): 50-63.

Oliveira-Filho, A.T. \& Fontes, M.A.L. 2000. Patterns of floristic differentiation among Atlantic forests in southeastern Brazil, and the influence of climate. Biotropica 32(4b): 793-810.

Oliveira-Filho, A.T.; Curi, N.; Vilela, E.A. \& Carvalho, D.A. 2001. Variation in tree community composition and structure with changes in soil properties within a fragment of semideciduous forest in southeastern Brazil. Edinburgh Journal of Botany 58(1): 139-158.

Palmer, M.W. 1991. Estimating species richness: the secondorder jackknife reconsidered. Ecology 72(4): 1512-1513.

Pereira, J.A.A. Efeitos dos impactos ambientais e da heterogeneidade ambiental sobre a diversidade e estrutura da comunidade arbórea de 20 fragmentos de florestas semidecíduas da região do Alto Rio Grande, Minas Gerais. Tese de doutorado. Universidade Fedeal de Minas Gerais, Belo Horizonte.

Rondon-Neto, R.M.; Botelho, S.A.; Fontes, M.A.L.; Davide, A.C. \& Faria, J.M.R. 2000. Estrutura e composição florística da comunidade arbustivo-arbórea de uma clareira de origem antrópica, em uma floresta estacional semidecídua montana, Lavras, MG, Brasil. Cerne 6(2): 79-94.

Souza, J.S.; Espírito-Santo, F.D.B.; Fontes, M.A.L.; OliveiraFilho, A.T. \& Botezelli, L. 2003. Análise das variações florísticas e estruturais da comunidade arbórea de um fragmento de Floresta Semidecídua às margens do rio Capivari, Lavras, MG. Revista Árvore 27(2): 185-206.

ter Braak, C.J.F. 1987. The analysis of vegetationenvironment relationships by canonical correspondence analysis. Vegetatio 69(1): 69-77.

ter Braak, C.J.F. 1988. CANOCO - A FORTRAN program for canonical community ordination by (Partial) (Detrended) (Canonical) correspondence analysis and redundancy analysis, version 2.1 Technical report LWA88-2, TNO, Wageningen, Institute of Applied Computer Science.

ter Braak, C.J.F. 1995. Ordination. Pp. 91-173. In: R.H.G. Jongman; C.J.F. ter Braak \& O.F.R. van Tongeren (eds.). Data analysis in community and landscape ecology. Cambridge, Cambridge University Press.

van den Berg, E. \& Oliveira-Filho, A.T. 1999. Spatial partitioning among tree species within an area of tropical montane gallery forest in south-eastern Brazil. Flora 194(2/3): 249-266.

Veloso, H.P.; Rangel Filho, A.L.R. \& Lima, J.C.A. 1991. Classificação da vegetação brasileira adaptada a um sistema universal. Rio de Janeiro, Instituto Brasileiro de Geografia e Estatística.

Zar, J.H. 1996. Biostatistical analysis. New Jersey, PrenticeHall.

Versão eletrônica do artigo em www.scielo.br/abb 